\title{
Hypnosis Measuring: The Pilot Study of Machine Learning Approach for Instrumental Control of the Trance Dynamics in Patients with Anxiety and
}

\section{Depressive Disorders}

\author{
Nikita V. Obukhov ${ }^{1,2 *}$, Irina E. Solnyshkina ${ }^{2,3}$, and Tatiana G. Siourdaki ${ }^{1}$
}

${ }^{1}$ Research Department, The Association of Experts in the Field of Clinical Hypnosis, Saint Petersburg, Russian Federation

${ }^{2}$ Department of Psychotherapy, Federal State Budgetary Educational Institution of Higher Education "Academician I.P. Pavlov First St. Petersburg State Medical University" of the Ministry of Healthcare of Russian Federation, Saint Petersburg, Russian Federation

${ }^{3}$ Department of Psychiatry, N.P. Behtereva Institute of the Human Brain of the Russian Academy of Sciences, Saint Petersburg, Russian Federation

*onvion24@gmail.com, +7-906-248-81-65, https://orcid.org/0000-0001-6876-4005

\begin{abstract}
Having measurable physiological correlates, hypnosis should be measurable generally itself. The precise, continual, quantitative assessment (versus phenomenological one) of a current trance level (i.e., "depth") is possible only instrumentally. We've shown that electrophysiological patterns of a trance are stable from session to session, but significantly vary among subjects. Hence, to measure the trance level individually we proposed the following Brain-Computer interface approach and tested it on the 27 video-EEG recordings of 8 outpatients with anxiety and depressive disorders: on the data of the first session using Common Spatial Pattern filtering and Linear Discriminant Analysis classification, we trained the predictive models to discriminate conditions of "a wakefulness" and "a deep trance" and applied them to the subsequent sessions to predict the deep trance probability (in fact, to measure the trance level). We obtained integrative individualized continuously changing
\end{abstract}


parameter reflecting the hypnosis level graphically online, providing the trance dynamics control. The classification accuracy was high, especially while filtering the signal in 1.5-14 and 4-15 Hz. The applications and perspectives are being discussed.

Keywords: hypnosis, trance dynamics control, supervised machine learning, brain-computer interface, spontaneous posthypnotic amnesia

\section{Introduction}

Despite the multiple approaches to understanding hypnosis that lie on the continuum between the polar views - the state theories and the non-state theories, considering hypnosis as a specific state of consciousness only can help to explore its nature as objectively as possible also using instrumental control of the brain processes. Such view corresponds to the latest official APA definition. According to it, hypnosis is a state characterized by "focused attention", "reduced peripheral awareness" and "an enhanced capacity for response to suggestion" (Elkins et al., 2015). Each of these three parameters is not discrete and hypothetically can be quantified. We may raise the question: "How much more absorbed has the hypnotic subject become after the trance induction than he (or she) was before it, how much has the ability to respond to suggestions increased?" etc. And since these basic components of hypnotic trance can be measurable, we would say that trance can be measurable itself. The question is, what is measured in this case? What increases when absorption progressively increases, the awareness of peripheral stimuli decreases, and the ability to respond to suggestions grows? Probably this parameter has been defined by the practitioners of hypnosis for many years as "depth" (Cardeña et al., 2013; Friedlander \& Sarbin, 1938; Weitzenhoffer, 1962), and they've been seeking the way to measure it (Lecron, 1953; Tart, 1978; Wagstaff, 2010). Despite the fact that there is no exact definition of this concept at the moment, it was intuitively clear for specialists and hypnotic subjects 
themselves that the "deeper" the trance is, the lesser the connection with the surroundings, the lower activity of consciousness appears, and the higher the degree of subjects' immersion inside their experience and concentration on the suggestion content turns out to be. The hypnosis depth is generally considered not to correlate with the resulting therapeutic effect. Probably, therefore this concept seems to escape from the attention of modern researchers. At the same time, there are recent studies that indicate the brain structural and functional correlates of the trance depth (McGeown et al., 2015). Accordingly, we share the opinion that deeper hypnosis can often have several advantages (Tart, 1978). Even the well-known nonstate theory supporters (Lynn \& Kirsch, 2005), point out that it can be more useful in some cases for the patient to experience deeper hypnosis. Reasonably, researchers have been interested in the aspect of depth for years, and it has led to the appearance of the concept of trance stages and the invention of multiple classifications of stages from mild to deepest (somnambulistic) (Council, 2002). In addition, if the question of depth was not of any practical importance, it would be pointless to develop the deepening techniques (Casiglia et al., 2012), that are recommended to perform after the trance induction in many manuals. Also, there is an idea that some phenomena can be observed only at a certain stage of hypnosis. The depth seems to determine the complexity and the quality of hypnotic phenomena, as well as the success of some types of suggestions (catalepsy, positive and negative hallucinations, etc.), and the more complex they are, the deeper the trance in which they can be reproduced (Tart, 1978). For example, negative hallucinations or spontaneous post-hypnotic amnesia have traditionally been associated with the deep levels of trance (Chertok, 1989; Council, 2002; Korger, 2007). Therefore, the ability to reach a certain depth determines the hypnotizability, and vice versa, thus, the hypnotizability can be a good predictor of the trance depth for a particular subject (Reis et al., 1975). There are mentions of a high correlation between the scores for the self-rating scales of the hypnosis depth and the 
scores for the scales of hypnotizability (Szabó, 1993; Tart, 1978), as well as the degree of the particular components that the hypnotic state includes (such as absorption or dissociation) and hypnotizability (Facco et al., 2017; Frischolz et al., 2015). The last one many studies indicate to be a stable characteristic of an individual (Elkins, 2021; Oakley \& Halligan, 2013). This also leads to the methods of a subjects' hypnotizability assessment with scales, where the more complex suggestion they can perform (in other words, the deeper they can go into trance), the more hypnotizable they are. Hypnotizability is not equal to suggestibility, however, it is closely related to it (De Pascalis \& Santarcangelo, 2020; Santarcangelo \& Consoli, 2018), and, therefore, to the characteristics of the suggestion effects (speed of achievement, stability, completeness, etc.). Thus, there is some advantage in being able to achieve deeper hypnosis. One of them is that the subject's attention in deeper hypnosis is focused not on the actual environment but strictly inside, and it's possible to feel the inner experience like a real one (Casiglia, 2016; Oakley \& Halligan, 2013; Williamson, 2019), up to the phenomenon of hallucinations, and in some extremely deep stages - even more realistically than the perceived reality. Greater hypnotizability has been shown to be characterized by the greater functional equivalence of the mental imagery and the real object perception (Ibáñez-Marcelo et al., 2019; Papalia et al., 2014; Santarcangelo, 2014; Spina et al., 2020). There are indications that maximum depth hypnosis is featured by a "presence effect", when the hypnotized person is "in the reality of the image", the image becomes sensory multimodal (Tukaev, 2020). Certainly, this can give a better result both in terms of a greater probability of therapeutic suggestions acceptance, and in work with a patient's experience, for example, in desensitization, PTSD treatment, rescripting, etc.

The subjective feeling of being in a trance is different from the daily waking experience (Cardeña et al., 2013; Rainville et al., 2002), and many subjects requesting hypnosis expect to experience some unusual sensations during the session. Therefore, the subjective impression 
of being deeply in a trance improves patients' compliance convincing them that hypnosis is really some special, enhanced, unusual therapeutic work - the work on the unconscious level, and is not just "imagination with closed eyes with the psychotherapist's voice assistance". We suppose there are additional advantages of deeper trances. In some cases, deeper hypnosis will be needed to achieve a sufficient effect, especially while suggesting anesthesia for performing abdominal surgery, any actions or sustained changes in behavior, new rational beliefs instead of long-standing cognitive distortions, aversive suggestions for addictions, rapid effects on autonomic-visceral functions (for example, blood pressure, intestinal motility, etc.), suggested illusions and hallucinations, or age regression, etc.

Due to these reasons, both for research and for practical purposes, it seems to be useful to monitor objectively the dynamics of the trance intensity (i.e., depth) in real time on a session in a particular patient and thereby to make some flexible process management. An experienced hypnologist can intuitively define how deeply the subject is in trance at the moment - based on the peripheral signs of a trance state, but this estimation is rough, approximate, in fact, only qualitative, and can be possible predominantly when the sufficiently pronounced and indisputable signs become already clearly visible. A more accurate, continual, and quantitative assessment can only be possible with instrumental measurement of the brain processes, and since hypnosis is a hypothetically measurable state of a subject's brain, we can try to find available methods of quantifying it. As for the electrophysiological studies, a large body of data on the EEG correlates of trance states has been accumulated to date. Many researchers point out that trances are characterized by an increased theta activity in various cortical regions (De Pascalis et al., 1998; Freeman et al., 2000; Jensen et al., 2015; Kropotov, 2009; Paoletti et al., 2020; Sabourin et al., 1990; Vaitl et al., 2005). There are reports of an increase not only in theta but also low alpha rhythms (8-10 $\mathrm{Hz}$ ) in hypnosis (Deivanayagi \& Fernandez, 2007), as well as the general tendency to rising 
of the slow-wave activity power (Jensen et al., 2018; Cordi et al., 2014). Since these correlates are also variable and measurable, one would assume that the level (depth) of trance correlates with changes in these parameters: for example, hypothetically, the deeper the trance, the higher the theta rhythm amplitude is. There are even more advanced studies that claim to identify relatively specific electrophysiological trance biomarkers, such as changes in functional connectivity in theta $(4-7.9 \mathrm{~Hz})$ and beta1 $(13-19.9 \mathrm{~Hz})$ bands in certain areas of the brain (Jamieson \& Burgess, 2014). However, it is important to understand that the spatial, frequency characteristics, and intensity of such changes will vary significantly among patients. To control the dynamics of the trance state in a particular subject in real time by measuring the amplitude of EEG waves we will have to monitor a huge amount of data because this activity consists of a large number of parameters that are absolutely individual for each patient. Moreover, even assuming that the power of rhythms more typical for trance (for example, theta) increases as its depth increases, it is not possible to define what exact level of depth this specific intensity of the rhythm corresponds to. In other words, it is unclear where the most informative changes will be (the spatial question), what exactly to measure (the frequency question), and what degree of trance the certain intensity of these parameters will indicate. The screenshot of the session shown in Figure 1 demonstrates the measurements of wave amplitudes that are recorded and displayed on the screen synchronously with the video in the bands of $1.5-4 \mathrm{~Hz}$ (delta), $4-8 \mathrm{~Hz}$ (theta), $8-12 \mathrm{~Hz}$ (alpha), $12-15 \mathrm{~Hz}$ (sensory-motor or low beta), 15-25 Hz (beta) and 25-45 Hz (gamma) during the patient's trance using a 21-channel EEG in our laboratory. The design constructed in the BioEra Pro 4.048 software is used (BioEra, visual designer for biofeedback, n.d.). In this case, to get information about the dynamics of the trance state it is necessary to monitor 127 curves and 21 periodograms simultaneously, which is extremely inconvenient and not very informative. 
In modern times, the study and use of Brain-Computer Interface (BCI) systems are becoming widespread (Ramsey \& Millán, 2020; Wolpaw \& Wolpaw, 2012). Machine learning algorithms of BCIs make it possible to determine the dependencies between various measurable patterns of the brain functional conditions and the mental states it is in at that moment (Kothe \& Makeig, 2013). The system learns to recognize a particular desired state and subsequently not only to distinguish it from any other but also to measure the degree of correspondence of the current state registered in the brain to the desired one. The interfaces using a non-invasive recording of the brain electrical activity (BCI based on EEG) are the most common now due to their affordability, small size, and safety for the patient (Bird et al., 2018). BCI based on motor imagery (belongs to the active type of BCI), the P300 evoked potential (belongs to the reactive type), and some others are well-studied and already actively included not only in research but also in clinical, and particularly rehabilitation practice (Carelli et al., 2017; Irimia et al., 2018; Naseer \& Hong, 2015; Ozkan \& Kahya, 2018). However, the so-called passive BCI (Krol et al., 2018; Zander et al., 2017) progressively evolves, and its function is to recognize various mental states, for example, neutral, relaxed, and concentrated (Bird et al., 2018), or neutral, positive and negative, and other types of emotional conditions (Bird et al., 2019; Laureanti et al., 2020), as well as mental singing, mental arithmetic, mental rotation (Naseer \& Hong, 2015), workload (Zammouri et., 2018), interictal and ictal periods in epilepsy (Giannakakis et al., 2019), etc. This expands the BCI using range and provides an opportunity to apply it not only to restore communication abilities and control external devices but also for detecting and evaluating a particular mental state. If hypnosis is presumed to be a special mental state, it also has to be characterized by certain patterns of a brain activity that are different from the ones in wakefulness and in sleep. So, we believe that it is possible to create a protocol within the passive BCI paradigm that could train the system to recognize and measure these multiple spatiotemporal and 
frequency patterns, collecting them into a single, individualized characteristic of a continuous quantitative assessment of the trance level at a particular moment, for us to watch this integrative output in real time during the session. This way the neurofeedback approach using BCI is implemented, but in this case, the feedback is perceived not by the patient themself, but by the hypnotherapist who attempts to control the trance more accurately based on the receiving information. We suppose that the ability to accurately and continuously quantify the hypnosis level in a subject in real time can not only be useful for research of the trance microstructure in different patients but also can give a therapist, who receives immediate information about the processes in the patient's brain, several advantages such as the increased competence in managing the therapeutic work and optimization of the session construction to achieve maximum effect.

Thus, our research aims to create a simple, available, and easy-to-use system that allows monitoring the trance state dynamics in a subject in real time on a session to control the process more flexibly and precisely for various research and therapeutic purposes. To achieve this goal, we used the passive BCI paradigm to discriminate between different mental states when registering a scalp electroencephalogram.

\section{Materials and Methods.}

\section{Main principle}

The main principle of supervised learning BCI (Liu \& Wu, 2012), is that we must show to the system, designate, mark the periods to register the brain activity that corresponds to the target state on a training session for this system to accurately predict the desired state during the subsequent measurements. So, using a certain number of training fragments of initial recording the system is trained to detect brain activity patterns typical for the target state, and then, detecting their varying degrees in subsequent measurements, it can judge how 
much the patterns observed at the moment correspond to this desired condition. Thus, for the system in the future to be able to measure the level (depth) of the patient's current state, in the initial (training) measurement we need to identify and label manually those periods of the session that correspond to a deep trance, and those that are related to the state of wakefulness. Their phenomenological attributes are required to relatively judge whether the present state is the target one, what session part it is observed at, and what conditions it should be discriminated from. As one of the main reference points which we can start from while creating an instrumental system for measuring the trance degree, as a sign that the subject is quite deep, we used the phenomenon of spontaneous post-hypnotic amnesia. We considered it as a relatively objective and the most reliable non-instrumentally determined sign of a deep trance, based on multiple data that this hypnotic phenomenon is typical exactly of the deep stages (Britannica, n.d.; Korger, 2007). We assume that hypnosis of even the strongest depth may not be accompanied by amnesia, but if it occurs in any part of the trance, we can say that the patient was deep enough in this period.

\section{Participants}

In order to develop and test the system, the study initially included 9 patients with anxiety disorders ( 3 men and 6 women, mean age $38.33 \pm 10.61$ years) who underwent up to 7 hypnosis sessions with synchronized EEG and video recording. The inclusion criteria were the age between 18 to 65 years, the presence of a diagnosis of anxiety or comorbid anxiety, depressive or somatoform disorders (to homogenize the sample) that met the corresponding ICD-10 criteria, and consent to participate in the study. All patients filled out an informed consent form approved by the Association of Experts in the Field of Clinical Hypnosis (Saint Petersburg) Ethics Committee. The exclusion criteria were severe cognitive or somatic impairment, anamnesis of epilepsy, psychotic episodes, as well as the absence of posthypnotic amnesia periods based on the patient's report as a result of the first session. EEG 
recordings of poor quality (a large number of artifacts, high electrode impedance) were excluded from the analysis. The initial number of EEG recordings obtained was 29 . We did not measure the patients' hypnotizability. The summary of research participants is presented in Table 1.

\section{BCI system}

The system consisted of equipment for synchronized EEG and video recording, as well as several types of software necessary to solve specific tasks in the sequential procedure for the EEG acquisition, its pre-processing, preliminary quantitative analysis, and mathematical calculations for the machine learning to be performed. For EEG recording, we used a Mitsar-EEG-SmartBCI 21-channel neurointerface (CE medically certified (MDD 93/42 / EEC), hardware sampling rate is $2000 \mathrm{~Hz}$ filtered down $250 \mathrm{~Hz}$, frequency range is $\mathrm{DC}(0)-70 \mathrm{~Hz}$ ) in combination with an elastic textile cap with fixing rings for point $\mathrm{Ag} / \mathrm{AgCl}$ sintered electrodes, located according to the international system 10-20 in positions: Fp1, Fpz, Fp2, F7, F3, Fz, F4, F8, T3, C3, Cz, C4, T4, T5, P3, Pz, P4, T6, O1, Oz, O2. The ground electrode was located in the AFz position, the reference ones were on the earlobes (positions A1, A2). A monopolar montage regarding the ear electrodes A1 and A2 was used. The impedance was maintained at a level below $5 \mathrm{kOhm}$. The video was recorded using a standard web camera. EEG spectral analysis with preprocessing was performed in the WinEEG software, version 2.130.101 (WinEEG Research Software, n.d.) marking of the calibration EEG recording for subsequent classifier training was carried out in the Matlab toolbox EEGLab 2019.0 (Delorme \& Makeig, 2004). The design construction used for the offline training session to make frequency and spatial EEG filtering, feature extraction, classifier training, classification accuracy testing, as well as online application of the trained model for predicting (and measuring) the desired state in subsequent sessions with patients, was carried out in the OpenVibe 2.2.0 (Renard et al., 2010). 


\section{Procedure}

Before the first hypnosis session, patients filled out the HADS (Zigmond \& Snaith, 1983), SCL-90-R (Hildenbrand et al., 2015), scales to quantify the severity of mental disorders and for further study goals. Also, before and after each session, they completed the "Feeling, Activity, Mood" (FAM) questionnaire (Доскин et al., 1973), and the situational anxiety subtest of the "Integrative Anxiety Test" (IAT-sa) (Бизюк et al., 2005). The last two instruments allow us to assess the current immediate state of a patient and have been used to assess the effect of each particular hypnosis session on patients by comparing the scores before the session and after it. Since data analysis using these questionnaires is beyond the scope of this article, we do not provide their detailed description here. We have previously published a study about the effects of a single hypnosis session on the mental state of the patients with non-psychotic psychiatric disorders in a multidisciplinary hospital, as well as about the effectiveness of short group hypnotherapy courses in these patients using the aforementioned scales (Krylov et al., 2020).

Each hypnosis session consisted of the following steps. After completing the questionnaires, the electrodes were placed to register the patient's scalp EEG, and the equipment was installed for video and audio recording of the session to be synchronized with EEG so that the video captured the head, trunk, and upper limbs. Then, in a comfortable sitting or lying position, a baseline EEG was recorded with the eyes closed for 3-5 minutes, both in silence and with environmental sounds of neutral character. After that, the patients underwent a standard hypnotic induction by an ESH-certified psychotherapist-hypnologist with the suggestion of physical and mental relaxation, followed by the trance deepening using descending the stairs metaphor, accompanied by counting with the suggestion to mentally descend the stairs deeper with each count. After the appearance of noticeable relaxation signs, such as "hanging" of the facial muscles, lowering of the mandible, in some cases with a 
slight mouth opening, a decrease in the frequency of respiratory movements, and a structure of breathing change (transition to slow diaphragmatic breathing), which considered by wellknown experts in the field of experimental hypnosis to be sufficient external phenomenological criteria for verifying the deep trance period beginning (Casiglia et al., 2018; Casiglia et al., 2019), for some additional time the suggestions to deepen and maintain this trance depth were given, with periodic repeated checks of rapport keeping by finger signaling. The rapport checking was done by a suggestion: "If you can hear me, let your unconscious mind move the thumb of your right hand". If the suggestion was executed, a conclusion was made about the presence of rapport. Further, therapeutic suggestions were made according to the treatment strategy developed for this clinical case. After this step, a patient was awakened from the trance by counting back, they provided feedback about the experience of the trance, and specifically, reported from which and to which moment they were amnestic about the content of the session. This was determined, for example, by what number was the last that they remembered while going down the stairs, and the number after which they started to remember the content of the session while awaking from a trance. After some time of body tonus and clarity of consciousness recovery, the patient filled out the FAM and ITT-sa questionnaires regarding the current state.

\section{The analysis of the obtained video recordings synchronized with the EEG was carried out}

\section{as follows}

Initially, it was necessary to test the hypothesis that at different sessions in the same patient, the period of being in a trance is characterized by the same patterns of brain activity, because only if it is correct, the use of a system trained in the first session to recognize any desired state can be possible to predict this exact state in subsequent sessions. This analysis was conducted in the WinEEG software version 2.130.101 (WinEEG Research Software, n.d.). The signal was filtered out in the $0.3-64 \mathrm{~Hz}$ range, the notch filter was $50 \mathrm{~Hz}$. Each of 
the patients' EEG recordings was cleaned from artifacts using the Infomax ICA decomposition method (Langlois et al., 2010). Based on the synchronized video, the two types of large sections were identified in them. The first type corresponded to the state, which we roughly called "non-trance" or "total wakefulness" - "W". It included the first 3-5 minutes of baseline registration, as well as the part of the session the patients had remembered identified by their report according to the above principle. The second type corresponded to the sections of "deep trance" (or "trance with amnesia" - "T") recognized based on spontaneously amnesic periods of the session, as well as several additional aforementioned signs (Casiglia et al., 2018, Casiglia et al., 2019), indicating a sufficient depth. With rare exceptions, the duration of both types of sections was more than 10 minutes. For each one of them, the averaged power of spectra (periodogram) was calculated using the fast Fourier transform (FFT): the sections were divided into epochs of 4 seconds, with epochs overlap of $50 \%$, and Hann time window. The spectra were calculated for standard EEG frequency ranges: Delta (1.5-4 Hz), Theta (4-8 Hz), Alpha (8-12 Hz), Sensory-motor or Low beta (12$15 \mathrm{~Hz})$, Beta1 (15-18 Hz), Beta2 (18-25 Hz), Gamma (25-45 Hz). After that, a statistical comparison (calculation of the difference) of the average values of the spectrum absolute power between the "T" and "W" regions in these frequency bands was performed, which provided a general impression of what brain activity patterns distinguish the trance from the non-trance period in the session under consideration. To assess the statistical significance of the differences between means, the Student's t-test was used. This procedure was performed for all the EEG recordings of each patient. The results obtained for each session in a given patient were compared with each other, and this allowed us to make an approximate generalized conclusion whether the brain activity patterns of a particular patient are replicated from session to session. 
The next step consisted of the following. After the first session with each subject, we got an EEG recording (with synchronized video and audio) to be used as a calibration file in the offline classifier training for the system to be able to discriminate (and measure) two conditions in the future online - on the second and the further sessions. That is why between the first and the second sessions of a particular subject it was necessary to train the classifier offline with the first session data. In this case, the signal underwent minimal pre-processing (mainly a notch filtration). Unlike the previous goal, we did not delete the artifacts here on purpose - for the file which the classifier is trained on to be as similar as possible to the signal in the subsequent online sessions where it would be impossible to get rid of artifacts in real time. Within each of the two types of periods in the first recording, we placed event labels corresponding to the period (state): event "W" and event "T", so that they can be used to specify short trial epochs. In the trance period, to be even more sure that the patient is really deep enough, we attached the "T" mark to the moments of visual signs of sufficient trance depth recorded on video and occurring immediately, such as, most often, to short-term involuntary muscle movements (hypnic jerks), unconscious (according to the patient's report after the session) opening of the mouth, other facial phenomena, e.g., pulling the lips into a tube, jaw movements, raising and lowering eyebrows, and less often, to significant changes in the type of breathing and even sudden snoring. At the same time, as it has already been noted, the control of maintaining the rapport with finger signaling had been constantly carried out to make sure that the patient had not fallen to natural sleep. We've been also convinced in this because during the trance period the hypnologist's speech purposely remained loud and clear enough for a naturally sleeping subject to awake, as well as because all the patients easily performed the suggestion to wake up on the reverse count, which was also purposely given in a normal, not different from the previous period voice tone and loudness. If the patient was in a state of natural sleep this suggestion wouldn't have a result. The "W" labels in the sections 
corresponding to the non-trans period were placed arbitrarily. All labels were located at a distance of more than 4 seconds from each other. Thus, the completely marked-up calibration file contained 20-25 event labels for each of the two conditions. We assume that an approach with the taking of only two types of classified states, representing the opposite poles of the neurophysiological continuum from full wakefulness to the almost maximum depth of trance, will be enough since the deepening of the trance is obviously expressed in the gradual moving of a patient from one pole of the continuum to the opposite one and associated with an interdependent decrease in the extent of the wakefulness patterns and an increase in the extent of trance ones. In an online session, this will be measured by a pre-trained Classifier Processor as a percentage ratio of the degrees of correspondence of the currently observed activity to one vs another state. So, for example, if at this exact moment the ratio of "full wakefulness - trance with amnesia" is estimated at 50/50\%, this means the middle subject's position on the continuum, i.e., the medium depth of trance. Therefore, we can assess the depth of the trance as a likelihood of correspondence of the patterns observed at the moment to the state "T".

In order to increase the classification accuracy during the classifier training, we applied spatial filtering of signals using the Common Spatial Pattern (CSP) method (Aydemir, 2016; Blankertz et al., 2008; Ramoser et al., 2001), to each calibration file. The CSP algorithm increases the signal variance for one condition while minimizing the variance for another one. In the OpenVibe software, we had constructed a scenario (a sequence of boxes that processes information in a certain way) that allows us to calculate the spatial filter coefficients (Scenario-I), and they will be determined not only by the event labels but also by the duration of the epochs related to these events, as well as by selected signal frequency range. To accomplish this, epochs of 4 seconds were allocated around each event label, so that the first half-seconds of the selected epoch preceded the label, and the remaining 3.5 
seconds followed it. This way we tried to cover by the analysis that brain electrical activity which was during the period that includes entirely any momentary event observed in the trance (for example, hypnic jerks). The four-second duration of the epoch seemed to us long enough to contain an acceptable quality and quantity of potentially detected patterns of the desired state, and quite short to have a fairly good time resolution while immediate observing the change in these patterns in a subsequent online session using the obtained predictive model. We had to determine how many spatial filters will be computed. This reflects the number of resulting channels to which the initial $(n=21)$ number of calibration recording channels is reduced after spatial filtering. The selected filter dimension was 12 (i.e., 12 resulting channels for each state).

Thus, in Scenario-I, the signal was divided into epochs according to the abovementioned principle that was used to calculate the spatial filter coefficients. To find the filters that facilitate the best two states discrimination, we calculated four variants of the CSP filters depending on the frequency range used: variant for the whole wide band $-1.5-45 \mathrm{~Hz}$, and also to find the highest classification accuracy, we tested three narrower bands: in the range from 1.5 to $8 \mathrm{~Hz}$, from 1.5 to $14 \mathrm{~Hz}$, and from 4 to $15 \mathrm{~Hz}$, since exactly low-frequency activity has been shown in the literature to be changed mostly during the trance development (Cordi et al., 2014; Jensen et al., 2018). For the signal filtering in the frequency domain, here and at all subsequent scenarios, we used the band-pass temporal filter by the Butterworth method, the filter order is 5. Using Scenario-I, we received configuration files containing these coefficients for each frequency band as a result of the spatial filter coefficients calculation. These files were used in the following scenario (Scenario-II), which is designed for feature extraction and classifier training. In Scenario-II, after frequency and spatial (with a previously calculated CSP spatial filters for a certain frequency band) filtering, the signal was divided into two groups of epochs (according to two types of states) with a duration of 4 
seconds in the same manner as in the previous scenario and according to the same principle.

Further, the feature extraction was performed for each of the two separated groups: the signal was split into blocks of 4 seconds every 0.5 seconds, and then the logarithmic band power was computed as $\log (1+\mathrm{x})$, where $\mathrm{x}$ is the mean of the squares of the signal in each of the blocks. This value was subsequently converted into a feature vector, which then went to the Classifier Trainer box. Thus, in the training process, the Classifier Trainer receives two types of feature vectors (corresponding to the state "W" and the state "T") and after its completion, it produces a configuration file based on the received data, which will be used during online sessions by the Classifier Processor box in the next scenario. For classification, we used one of the most common algorithms - Linear Discriminant Analysis (LDA). The usage of the proposed method in the therapeutic context assumes that the calibration file will be an EEG obtained at the first session, but for the research purposes in our work to make the sample of EEG recordings for the classification accuracy calculation more representative, we ran through the Scenarios-I and -II all EEGs of each patient. As mentioned above, to find the coefficients of the CSP filter and then train the LDA classifier, we filtered the signal in four different frequency ranges: $1.5-45,1.5-8,1.5-14$, and $4-15 \mathrm{~Hz}$ and for each of these variants, the classification accuracy was calculated using a 10-fold cross-validation test. It was considered impractical to estimate the classification accuracy in narrow frequency ranges for each band separately (i.e., for theta, alpha, etc.) since using a calibration model trained on a very narrow range can cause that in the online session any stochastic power changes only in this range will be interpreted as enough indication of the desired state (e.g., trance, "T"), and it will be predicted incorrectly, but trance in each subject, as we assume, is characterized by a combination of changes in the power of rhythms in several different ranges simultaneously, forming individual electrophysiological patterns of hypnosis. Estimating just too wide a frequency range, such as $1.5-45 \mathrm{~Hz}$, also has its disadvantages. So, when a patient goes into a 
trance, the power in one narrow band (e.g., theta) increases, and in another (e.g., alpha or beta) decreases, which hypothetically can cause that the general changes in the signal power in the entire wide band would be compensated and become "invisible" for classification. This had to be tested, so alongside assessing a wide frequency range $(1.5-45 \mathrm{~Hz})$, we decided to take three little narrower ones.

Then the classification model obtained from this method was applied in the second and the following sessions to monitor the trance dynamics in real time. Scenario-III allowed us based on this model to predict what of the two states (and with what probability) the patient was in, and it involved the online registration of the patient's EEG. Here the acquired in real time signal was filtered out in the selected frequency band, passed through a spatial filter previously calculated in Scenario-I, then it went through the same (like in Scenario-II) transformation steps for feature extraction and the making of the feature vectors, which were then sent to the online Classifier Processor contained the configuration file of our model produced in the Scenario-II. This allowed the Classifier Processor to judge based on the comparison of data from this file and the current data about the correspondence of the incoming feature vector to one of the two states in real time with a certain probability. As a result of the operation of this scenario with a raw EEG, the system predicted the patient was either in the "W" or in the "T" state, which gave Probability Values as an output parameter. This output showed the classification algorithm status in the form of a matrix of values, which reflected the interdependent probabilities of matching current patterns of brain activity to one state and another. For visualization convenience, we selected only the state "T" probability from the matrix and displayed this value fluctuating in time from 0 to 1 by an online graph using the Continuous Oscilloscope box. At that point, the closer the value was to 0 , the more the state corresponded to full wakefulness and, accordingly, the closer to 1 , the more likely the trance with amnesia was. Thus, instead of a large number of disparate and not 
very informative variables, we received a single integrative individualized continuously changing (from 0 to 1 ) parameter displayed for the hypnologist in the form of a curve, and it was possible to monitor "the behavior" of this graph in time during the session.

The choice of one of the four frequency bands and the corresponding classification model (that is, a combination of configuration files for the spatial filter and Classifier Processor), which we worked with further during a particular online session, presupposed a primary visual assessment of how accurately the model predicted the state "W" while the baseline EEG was being recorded with patient's eyes closed in the very session beginning. The default band was 1.5-45 Hz. However, if it was clear from the very beginning (while awake) that the curve in the Continuous Oscilloscope predicting the patient's trance state was too far from zero or its values even exceeded 0.5 (i.e., $50 \%$ probability), we changed the frequency band and, accordingly, the classification model. So, by alternating testing, we selected the frequency band and the related model that predicted the minimum trance probability displayed as an online graph with the curve closest to zero. This was the sign of the most accurate predictive model, and it had to be used in the session. Having chosen a model from the very beginning, we conducted an online session and as a result obtained a curve reflecting the changes in time of the probability of being the patient in the " $\mathrm{T}$ " state, which can be interpreted as the level of the hypnosis depth - the higher the probability, the deeper the trance (or to be more exact, the higher the probability of amnesia in this period of the session). We called this curve "predictive". Its data were then (while the post-session analysis) visually compared in time with the clinical assessment of the trance dynamics and depth according to the patient's report about the period of amnesia, visual peripheral signs of deep hypnosis caught on video, etc. This allowed us to make a preliminary conclusion about how well the measured parameter agreed with the phenomenology of the session and described it. 
For a more accurate, quantitative assessment of our classification model effectiveness, we tested its predictive performance not only on the data of the calibration (first) session itself (using the 10-fold cross-validation test) but also on new results: the data of the online (second and subsequent) sessions. To make this procedure, the obtained EEG recordings of the online sessions were marked according to the same principle used for the first (calibration) ones. Since the results of the online session had been already known in the form of the acquired "predictive" curve, to eliminate bias in the process of the file marking, the positioning of the event labels "W" and "T" was performed by a specialist who had not been to this session and therefore had no idea about the predictive results obtained in it. This was done based on the video and the patient's report about amnesia only. Next, the marked file was passed through Scenario-IV, which was almost completely the same as Scenario-III, with the only difference that the data source was not the raw EEG of the patient in real time, but its labeled recording. This scenario uses the Classifier Accuracy Measure box, which got information simultaneously about the state the current epoch corresponded to, based on the file marking (the real state) and the state the Classifier Processor predicted at a moment using the calibration model (the predicted state), and the box compared this information. The classification accuracy is measured as the percentage of coincidence of the predicted states with the real (i.e., based on the markup) ones, that is the percent of the correctly predicted states for the entire session (Kohavi \& Provost, 1998). At this stage of our analysis, we tested the classification accuracy for each of the four models (according to the four frequency bands) that were obtained from patients.

In addition, in the following, we acquired as well the proper classification models for each of the online sessions by the training based on their marked EEGs, put them into Scenario-IV, and passed exactly the same data on which these models were trained through this scenario. This way, afterward, we could get a curve that reflected the dynamics of the 
trance in the online session that had passed as it really was, i.e., with maximum accuracy (we called it the "native" curve). Then, the configurations of the "native" and "predictive" curves were visually compared. This was done to additionally assess how accurately the model trained on the first session data was able to reflect the actual picture, i.e., how good its predictive ability was.

\section{Results}

All the recordings were free of oculographic artifacts, because, as we have noticed, patients were already with their eyes closed during the baseline registration of the EEG in the waking state, as well as after the initiation of the hypnosis induction. Patient T (and, therefore her first EEG recording) was excluded from the study because there were no periods of amnesia as the session result. Also, one of the recordings, that was of patient E (session \# 5), was excluded from the analysis due to the progressively increasing myographic artifacts in the anterior leads during the session and increasing impedance on several occipital and parietal electrodes, followed by the complete loss of contact. Therefore, the total number of EEG recordings from the remaining 8 participants was 27.

\section{Results of the repeatability evaluation of the deep trance electrophysiological patterns in patients from session to session}

First and foremost, we tested our hypothesis for the reproducibility of the brain activity patterns in the same patient from session to session. Using WinEEG software, we made a statistical comparison (calculation of the difference) for the average values of the absolute spectrum power between deep trance and wakefulness periods (trance spectrum minus wakefulness spectrum) in the standard frequency ranges for each EEG recording of each patient and visualized it with topograms showing the degree of these differences. This approximate general assessment allowed us to define areas and frequency bands with the 
most significant changes in the spectrum power in this patient at the current session when they had gone down into a trance. This gave a rough impression about the patterns of the brain activity typical for trance in a given patient at a given session, and they were expressed in the tendency for the power of the rhythms to change in some direction. Figure 2 shows the examples of such topograms for three patients at 3 different randomly selected sessions for each of these patients. Changes in the power of rhythms are displayed on topograms in color according to the graduation of a nearby color scale. For example, as we can see from Figure 2, in patient $\mathrm{A}$ the transition to trance is associated with a very large decrease in the alpha range activity, some decrease in the beta- 2 rhythm in the occipital regions, a noticeable increase in theta, and even slower activity in the middle and mid-frontal regions, some increase of the sensorimotor and beta- 1 rhythm in the frontal region. This pattern tends to be observed in each of the sessions. Other patients demonstrate some similar changes (the slowwave activity increase in different areas of their brain), which correspond to the literature data about the electrophysiological correlates of the trance states, nevertheless, they show quite clear differences from each other. For example, patient G, unlike all the other participants of the study, did not demonstrate a decrease in the alpha rhythm in the occipital region, but, on the opposite, she showed its increase, alongside an increase in the power of slower rhythms.

It is remarkable that, as we can see in the example of patient $\mathrm{E}$, the patterns of changes in the rhythms typical for the trance of a particular patient show great stability over time and are reproduced, even if more than a year has passed between the measurements. In addition, WinEEG software allows us to calculate the difference in the average power of the spectra in other frequency ranges, up to ranges with a step of $1 \mathrm{~Hz}$. We do not present the data of such an analysis here due to the very large number of topograms. Thus, based on the analysis of the topograms of all the 27 hypnosis sessions, we can make a general preliminary 
conclusion that: a) the patterns of the brain activity that characterize being in a trance for a particular patient are consistently reproduced from session to session, which suggests that b) in general, using the EEG recording of any patient's hypnosis session as a calibration file, we can expect for the system trained on it to effectively detect the desired states in subsequent sessions; c) although the patterns that characterize trance state may have certain similarities in different patients (e.g., an increase in activity in the theta range), at the same time, there are significant differences between the subjects, which tells us that d) it is impossible to use any general approach to evaluate and "measure" trance for all people, and an individualized assessment is required.

\section{Results of the 10-fold cross-validation test of wakefulness and deep trance discrimination}

\section{accuracy}

Table 2 shows the obtained by Scenario-II results of this classification accuracy assessment in patients at each of the sessions for four frequency band variants. As usual, the results of such analysis are given in the form of the average value of the classification accuracy among the ten partitions formed based on the marked file, and the corresponding standard deviation. As can be seen, the classification accuracy in all patients and all the tested frequency ranges is quite high, in the vast majority of cases, exceeding $85 \%$. This confirms the presence of definite electrophysiological patterns in the trance state, significantly different from those observed in wakefulness, which can be well recognized by the chosen algorithms. For some sessions, the accuracy turned out to be absolute (100\%). At the same time, despite the cross-validation test is quite a reliable method, on the one hand, we took into account the OpenVibe software manufacturer's warning that the results of this calculation may be too optimistic and on the other hand, we had to keep in mind the over-fitting phenomenon (Santos et al., 2018) possibility. Consequently, these results were not comprehensive, and it 
was also necessary to test the accuracy of the obtained on the first session model on new data, i.e., data from the second and subsequent sessions.

\section{Results of visual (qualitative) testing the proposed methodology online (at the second and subsequent sessions)}

As mentioned above, during each session, starting from the second one, in real time we received with Scenario-III a graphical representation of our model (obtained in the first session with Scenarios-I and -II) in the form of a "predictive" curve, reflecting the change in time of the probability of that individual brain electrical activity patterns related to the "T" state. In fact, we were able to estimate how deep our patient was at any moment - the higher the position of this curve was, the more likely spontaneous amnesia in this period appeared, and respectively the deeper the trance. As an example of how the predictive model works in real time, Figure 3 shows a screenshot of the graph reflected changes in time of the "T" state probability values, taken at the end of the online session with patient $\mathrm{A}$ on the seventh (last and shortest) visit. In this example, the signal was filtered out in the $1.5-45 \mathrm{~Hz}$ frequency range. Due to the significantly high tendency of the values to fluctuate, for the convenience of displaying data over a large time interval (in the example -18 minutes), to smooth the curve in the feature extraction process, in some cases we allowed ourselves to use in the Scenario-III averaging the signal over an epoch not of 4 seconds, but 15 seconds. The time interval between the two consecutive epochs remained as in the calibration process (like in Scenario-II, i.e., 0.5 seconds). This change practically did not affect the informativeness of the data, because the feature vector, which is the basis for the Classifier Processor to decide the current state and its probability, is an averaged value. Obviously, if an epoch of 15 seconds in an online session has the same "quantity" of certain state patterns as an epoch of 4 seconds in the training session had, then after averaging it will give almost the same feature vector value as it was on calibration session for the correct classification. The resulting 
"predictive" curve very accurately describes the phenomenology of the session and allows us to evaluate the trance dynamics. As can be seen in Figure 3, there are several quite distinct periods in the behavior of the curve. For about the first 200 seconds, the probability values of the "T" state are at a low level, which corresponded to the baseline EEG recording period calm wakefulness with eyes closed. Then inducing trance suggestions followed. Since it was the seventh session in this patient, and he had already developed the skill to quickly achieve a deep trance, almost immediately the curve rises quite abruptly, but for some time (about from 200th to 500th seconds), it demonstrates wave-like behavior. This was expressed in the patient's further report that after the induction beginning, he periodically "plunged deeper", "switched off", but briefly "surfaced" from time to time and that he remembered this session part in fragments (the phenomenon of partial amnesia). This part of the session could be called the period of development (formation) of a deep trance. From about the 500th second, the curve values stabilize around 0.8 , keeping only minor fluctuations, ad the patient was completely amnestic about this part of the session. The patient's rapid entry into a deep trance, which we observed by the curve behavior, allowed us to save time and quite briefly and concisely conduct the therapeutic work in hypnosis, make appropriate suggestions, and, since about 900th second, to suggest an exit from the trance by the method of reverse counting from "5" to "1" with full awakening on the count of "1" (without opening the eyes to avoid oculographic artifacts). The awakening suggestion stage lasted for about 1 minute. However, as can be seen from the curve, up to the moment the hypnologist pronounced the number "1" (959 s), the patient had been in a deep trance, and immediately after that, there was a sharp ("avalanche-like") exit, followed by some time of post-trance baseline EEG registration with the eyes closed (from 960 to 1105 seconds).

Similar results were received for each patient from the second and the following sessions if a suitable classification model was used. While comparing the curve data with the 
phenomenological characteristics observed, in all the cases we found a coincidence of the time when the curve was, on average, consistently high enough (approximately, above 0.7), with a completely amnesic period, as well as the period of deep trance peripheral signs (Casiglia et al., 2018; Casiglia et al., 2019), presence, which indirectly indicates quite a high efficiency of measuring the hypnosis depth. However, a quantitative analysis of this approach efficacy was also needed.

\section{Results of quantitative evaluating the accuracy of the classification model on the second and subsequent sessions data}

As noted above, the EEG recording obtained at each online session was marked up by an independent expert and used to evaluate the accuracy of the classification model and build a "native" curve for each session using Scenario-IV. The results of the second and subsequent sessions for each patient are shown in Table 3. As had been expected, the accuracy is lower than that evaluated by the 10 -fold cross-validation test, and this reflects the natural variability of the electrophysiological characteristics of the different sessions. Nevertheless, the classification models from patients $\mathrm{G}, \mathrm{N}$, and $\mathrm{V}$ for all the four frequency ranges gave very high accuracy, in some cases reached values above $95 \%$. In patients $\mathrm{A}$ and $\mathrm{O}$, only one of the four bands (1.5-8 Hz is for patient $\mathrm{A}$ and $1.5-45 \mathrm{~Hz}$ is for patient $\mathrm{O}$ ) gave unsatisfactory results, while all the others had high predictive power. Two bands gave good results in patients $\mathrm{S}(1.5-8$ and $1.5-14 \mathrm{~Hz})$ and $\mathrm{C}(1.5-45$ and $4-15 \mathrm{~Hz})$. The greatest difficulties occurred only with patient E, where the classification accuracy was quite high only in the 4$15 \mathrm{~Hz}$ band. We assume the reason for this situation is that she was the only patient in our study whose experimental conditions were maximally different from session to session: the room, the body position had been changing (three sessions, including the calibration one, had been conducted in a sitting position, the other three had been conducted in a lying position), and there were very long intervals between the visits (the gap between the first and last 
sessions was more than 1 year). The majority of experiments with her were accompanied by the artifacts both in the low-frequency (approximately $1.5-3 \mathrm{~Hz}$ ) and in the high-frequency (more than $18 \mathrm{~Hz}$ ) range. The high-frequency ones were due to the myogram, which most likely occurred because of the gradually growing uncomfortable position of the head during the session as a result of increasing relaxation of neck muscles. Because of the large number of artifacts and the loss of contact on one electrode, one of the sessions (\# 5) with this patient was excluded from the analysis. All of this led to that the EEG calibration recording (the first session) gave a classification model that was valid only in the band free of both low and high frequencies, i.e. in the range from 4 to $15 \mathrm{~Hz}$. As we can see from the table, in this band there was not only high classification accuracy but also very high stability of this accuracy from session to session $(\mathrm{SD}=1.9)$. We could detect this band at the beginning of our online sessions with her and use it there.

The lack of classification accuracy in the $1.5-8$ and $1.5-14 \mathrm{~Hz}$ ranges in patient $\mathrm{C}$ was also associated with low-frequency artifacts.

As an example of the results for visual comparison of the "native" and "predictive" curves of trance dynamics, Figure 4 shows the "native" curve obtained by passing the EEG recording of the seventh session with patient A through a classification model trained on the same session data itself using the frequency band 1.5-45 Hz. By comparing the graphs in Figure 3 (the "predictive" curve) and Figure 4 (the "native" curve) we can clearly see that the configurations of the curves coincide to a large degree. Figure 4 shows the periods of trance dynamics (the baseline at the beginning, the period of trance development with its wave-like run, the period of stable deep trance, the "avalanche-like" exit, and the baseline recording at the end of the session) that are the same as we had been able to observe earlier during online session relying on "predictive" curve behavior. Similar results were found in such analysis with all other patients if the frequency band that gave the most accurate classification model 
was selected. This analysis allowed us to assume that the low-frequency artifacts in patient $\mathrm{E}$ could be due to such a common phenomenon as drift (trend) (Driel, 2021) because the comparison of the "native" and "predictive" curves showed that the "predictive" curves of the second (on the 1.5-45 Hz) and third (on the 1.5-45 and 1.5-14 Hz) sessions had a very similar shape to the "native" curves, but with the only difference - they were strongly "raised" above the zero value. The classification accuracy turned out to increase greatly and become acceptable if during the offline processing of the EEG recording of these sessions in Scenario-IV with these bands while passing through the predictive model, a certain constant value was subtracted from the feature vector (see the notes to Table 3).

Thus, in all the cases of our study, we were able to accurately predict what state the subject was in at a given moment in an online session using a pre-prepared classification model, even despite the artifacts. The data in Table 3 shows that each patient had its own "preferred" frequency band where the classification model was the most accurate. For example, for patient $\mathrm{A}$ it is $1.5-14 \mathrm{~Hz}$, for patients $\mathrm{G}$ and $\mathrm{S}$ it is $1.5-8 \mathrm{~Hz}$, etc., which reflects the aforementioned individuality of the hypnotic state patterns. At the same time, when analyzing the classification accuracy for each particular band, summarizing the data of all the sessions conducted (see Table 3 "Average for all sessions"), we can see the range from 1.5 to $14 \mathrm{~Hz}$ occurred to have the highest and quite stable accuracy. The 4-15 Hz band gives similar results.

\section{Discussion}

The global thesis that hypnosis is exactly a state characterized by signs of brain electrophysiological activity, which is different from that in wakefulness, is confirmed by the results of statistical comparison of the average absolute power of the spectra between the deep trance and wakefulness periods in standard frequency ranges, and this is in good 
agreement with multiple literature data. This conclusion is augmented by the fact that the accuracy of wakefulness and trance with amnesia classification calculated by the 10 -fold cross-validation test occurred to be very large almost without exceptions. Possibly, this was due to the tendency of the software algorithms to give optimistic calculation results, so that in some cases the accuracy was estimated at $100 \%$. It is also probable to be due to the overfitting phenomenon (Santos et al., 2018), which was taken into account by us. Moreover, it is reasonable that these results exceed those results which were obtained when evaluating the model accuracy on the new data because the patterns of some kind of state in the same session are certainly more similar than in different sessions in a particular patient. Nevertheless, this fact directly demonstrates that if we take some separate session, the classifier can discriminate our states within it with almost no exceptions with high accuracy, and this once again confirms the thesis that hypnosis has clear electrophysiological characteristics that are different from wakefulness. This also indicates that any session can be used as a calibration one.

In addition, the analysis of the difference of the power of spectra allows us to augment this conclusion by that the EEG patterns observed in hypnosis tend to be reproduced in a patient from session to session, i.e., they are stable, even for a very long time intervals (more than 1 year) (see Figure 2). It is important to emphasize that when comparing these patterns in general with each other in different patients, both distinct similarities (such as a tendency to increase the slow-wave activity, etc.), and clear differences (for example, in the behavior of the alpha rhythm) can be found. It is quite reasonable that if the brain activity patterns typical for hypnosis were not stable from session to session, the models created on the first session data to predict trance with amnesia would after that show ineffectively, giving low classification accuracy, and would poorly describe the phenomenological manifestations. However, our results demonstrate that the development of accurate models that cope well 
with these functions is real and that the classifier trained in the first session can recognize the target electrophysiological activity well in the future, providing the opportunity to monitor the trance state dynamics in real time. The results of testing these models also confirm the thesis, on the one hand, about the similarity of hypnotic patterns in different subjects (because the models trained on bands covering theta and alpha activity tend to have the greatest accuracy), and on the other hand, about the significant variability among patients concerning the exact frequency range which we can get the greatest accuracy at. The last makes it impossible to use the same template method for all patients to predict the hypnotic state (for example, by the level of theta activity) and requires an individualized approach.

We also showed that the low- or (and) high-frequency artifacts can make the predicting quality ineffective in online sessions. Consequently, for the BCI paradigm to be used in work with hypnosis, we recommend creating conditions with a minimized appearance of artifacts probability, i.e., try to conduct sessions in the same room, body position, etc. We can also recommend pre-training several models on different frequency bands (for example, four) while calibrating, as it has been done in our study, and if the artifacts could not be avoided, and the initially applied model at the very beginning of the online session demonstrates itself poorly, providing an incorrect waking state prediction, then it is necessary to replace it immediately with another one that has been trained on a narrower frequency band, excluding the slow waves (which may be associated with drift) or high-frequency activity (related to the myogram). The second way to cope with this problem and get satisfactory data in an online session is, as previously noted, to correct the scenario by subtracting an empirically selected constant value from the feature vector, thus, eliminating the drift.

The obtained in the online classification process complex parameter of Probability Values is displayed in real time in the form of a "predictive" curve, which is provided as a 
kind of feedback, but for the hypnologist and not for the patient themself. Therefore, the curve behavior reflects the level of correspondence of the brain electrical activity registered at the current moment to the trance with amnesia. As we can see, despite certain fluctuations, it maintains common quite a smooth and continuous trend without sharp drops and spikes. The curve describes the phenomenology of trance development and maintenance (see Figures 3 and 4). At first, its position is close to zero, which reflects the stage of wakefulness. Then, there is a period of gradual rise to values exceeding 0.7 . Further, we observe for some time an unstable trance, which looks like an upper position of the curve interrupted by several episodes of a short-term decrease followed by a progressive return to the upper level. According to the patient's report after the fact, this period is characterized by partial amnesia, and only after that the trance is stabilized (the stage of complete amnesia) and, as a reflection of this, the curve for some time is continuously above 0.7 until the very exit from hypnosis. The execution of the suggestion of wake-up on a certain pronounced number is reflected on the graph as a quick drop of the curve to the level as of the session beginning. Such continuity in the "predictive" curve behavior, consistency, and good correspondence with the logical development of phenomenological characteristics makes applicable our assumption that it is possible and quite enough to take only two polar states for the calibration model training (full wakefulness - "W" and trance with amnesia - "T"), and in this case the trance deepening will be expressed in a gradual transition from "W" state to "T" one.

An experienced hypnologist by an external subjective assessment can define what state the subject is in only approximately, with some probability, and could precisely determine only total wakefulness and the deepest trance. However, it is impossible to know exactly what is happening between the poles of this continuum, how the trance is developing between them because it is difficult to assess it by eye. The system designed in our study makes this assessment more objective and provides an opportunity to monitor the dynamics 
of the depth, quality, and "quantity" of trance in a more refined and detailed way. The behavior of the "predictive" curve, its tendency to decrease or increase can give a lot of additional important information. This raises the question of why we need this information and how we can use it.

Answering this question, we can say that, firstly, we have got a tool for quantifying trance, "measuring" it, and analyzing its dynamics both during hypnotic work and after the session, as well for fundamental research purposes. We can see more explicitly that hypnosis is a very heterogeneous phenomenon. It has the qualitative characteristics, microstructure, "anatomy", where the phases can be recognized (the period of dipping into a trance, the periods of forming, stabilization, exit, etc.), and also it has some features, e.g., a tendency to undulate during the forming period, a certain speed of deepening the state or exit from it, and so on, thus, the information that was not available during external visual observation appears. Secondly, the system we have developed can contribute to clinical work optimization, which is expressed in many aspects, the central one is that the ability to more precisely control the level of hypnosis depth allows us to influence its degree or to use knowledge about the moments of the maximal depth on practice. In the introduction, we tried to show that deeper trances can have several therapeutic benefits. As mentioned, trance is prone to fluctuate, and when we have a tool to monitor this process, it becomes possible in real time to almost instantly detect the optimal periods for giving the most difficult to accept and fulfill suggestions (changes in old habits, behavior patterns and stable irrational cognitions, aversive suggestions for addictions, vegetative and visceral effects, etc.). The trance deepening, in fact, is an increasing concentration on the suggested content (i.e., absorption) and decreasing awareness of the competing irrelevant external information, which hypothetically should cause an increase in the strength of the suggestive effect. 
In addition, the phenomenon of amnesia itself can be quite useful in these cases. For example, in a cognitive-oriented approach, even if the patient agrees very well with the new rational beliefs at the logical level, their assimilation by deeper, implicit levels of the mind often meets great resistance. That is why, it seems to us useful while suggesting these cognitions and behavioral changes in hypnosis, to develop amnesia for the received suggestions to minimize consciousness intervention, critical attitude, and resistance to them.

Watching the "predictive" curve can allow us to detect the correlation between the verbal or nonverbal therapist's behavior and the reactions of the patient's brain, which can help the therapist to flexibly respond according to the individual needs of this patient in trance by selecting words, intonations, the pace of speech and other parameters of the session management. Also, we can immediately detect initial signs of possible trance disturbance and restore it quickly with the subsequent appropriate suggestion, as well as use the deepening by ratification, when the curve behavior shows the desired for us trend. The optimization of clinical work is also expressed in that the system developed allows us to measure the trance physiological characteristics, which, in turn, can be associated with certain therapeutic effects. For example, there may be a hypothetical relation between a greater amount of time with deep trance in some particular session and a greater anxiety reduction after it (which certainly needs to be tested). This will provide a potentially better understanding of which of these characteristics need to be strengthened (for example, by suggestion) and which ones need to be weakened for intervention to be as effective as possible. In addition, our approach helps to quickly assess hypnotizability, e.g., by the subject's capacity to maintain for a more or less long time quite a high level of trance with amnesia during the session.

An important effect of using our system can be an increase in the competence of the specialist, which is expressed in the training of understanding ("feeling") the trance dynamics (because the peripheral manifestations of the patient's condition fall behind the cerebral ones) 
and strengthening the ability to more skillful monitor the external signs that correlate with the changes in brain activity. This system can also become the basis for creating neurofeedback protocols for teaching patients to go into a trance on their own, where the feedback parameter will be the data of the "predictive" curve presented in auditory or tactile form.

\section{Conclusion}

Thus, the electrophysiological patterns of the hypnotic state in patients have been shown in this study to be quite distinct, stable in time from session to session, even over long intervals, reveal several similarities among the subjects but at the same time characterized by a great individuality. Consequently, it is possible to create a system on the principle of passive BCI with supervised learning, where a classification model is created based on the electrophysiological data of a session, and this model allows us to predict the state of wakefulness and deep trance with a certain probability in subsequent sessions, providing the only integrative and individualized parameter that quantitatively describes the level of trance state. Its continuous change helps the hypnologist to monitor precisely the session dynamics and use the data obtained to optimize therapy, as well as to theoretically study the microstructure of hypnosis.

\section{Limitations}

The limitations are the small sample size with a heterogeneous number of experimental sessions (some patients underwent only two sessions), the presence of artifacts in some EEG recordings, which, of course, affected the quality of recognition of the desired mental states. The probability of noise occurrence dictates the need for careful frequency band selection for the model to be trained. In addition, this problem can be solved by further developing and integrating the online algorithms for eliminating artifacts from the EEG into the scenarios. The main limitation of our study is that it involved only those patients who 
were able to develop the phenomenon of spontaneous posthypnotic amnesia. However, posthypnotic amnesia is just a particular instance of some target condition that the researcher or clinician would like to be able to detect in an online session. Therefore, the flexibility of the system is that while training the classification model, the researcher can assign any state or phenomenon they want to predict on further sessions as a target one.

Further research is necessary to test more advanced feature extraction methods that could use the overall changes in the spectrum power structure between trance and wakefulness, that is, as a general trance pattern, they detect not just a change of signal power in a wide frequency band, but combinations of power changes in different narrow ranges (e.g., an increase in theta + a decrease in alpha and beta). This means creating a scenario that calculates CSP filters for each narrow band, and then calculates the power of the signal filtered by the spatial filter for each band separately, when the values of these powers are collected in a single vector for one of the two states. However, this may require a lot of computing capacity and overload the operating system. Also, the disadvantage of this approach is the inability to quickly replace the model if at the beginning of the online session the initial one was recognized to be unsatisfactory. We consider it an incorrect strategy for feature extraction to use the ratio of the powers of some frequency ranges since in this case, we bring in our subjective assumption (bias) about what exactly ratio of randomly and arbitrarily selected bands should be significant for the classification and do not allow the system itself to decide what is important for classification. Therefore, the method we initially selected for feature extraction, when we trust the system as much as possible for it to find the difference between the two states, seems to have a large number of advantages. In further research, it is also necessary to test alternative methods of classifying states (e.g., using the methods of Support Vector Machine, Multilayer Perceptron, or using ensembles of classifiers). 
In addition to increasing the sample size, adding online algorithms for eliminating artifacts, testing other ways for feature extraction and other classification methods, the further development of our study also includes the analysis of the correlation of electrophysiological parameters with the hypnosis session clinical effects (using the results of the FAM, IAT-sa questionnaires, SCL-90-R and HADS) and the development of hypothetical personalized trance management protocols based on feedback using the machine learning paradigm for patients' self-application (i.e., the development of a personalized alternative to alpha-theta training).

Acknowledgments

We thank the head of the psychotherapy department of the Academician I.P. Pavlov First St. Petersburg State Medical University Gelera U. Utemisheva, the scientific curator of the department prof., Vladimir I. Krylov, MD, PhD, the president of the Association of Experts in the Field of Clinical Hypnosis, prof., Rashit D. Tukaev, MD, PhD, the chairman of the Association of Experts in the Field of Clinical Hypnosis Svetlana V. Khetrik.

Declaration of interest statement

The authors declare no conflicts of interest.

The work has not been funded by any organization.

\section{References}

1. Aydemir, O. (2016). Common spatial pattern-based feature extraction from the best time segment of BCI data. Turkish Journal of electrical engineering and computer sciences, 24(5), 3976-3986. https://doi.org/10.3906/elk-1502-162

2. Bird, J. J., Ekart, A., Buckingham, C., \& Faria, D. (2019). Mental Emotional Sentiment Classification with an EEG-based Brain-machine Interface. The International Conference on Digital Image \& Signal Processing (DISP'19), Oxford University. 
3. Bird, J. J., Manso, L. J., Ribeiro, E. P., Ekárt, A., \& Faria, D. R. (2018). A Study on Mental State Classification using EEG-based Brain-Machine Interface. 2018 International Conference on Intelligent Systems (IS), (pp.795-800). IEEE.

4. Blankertz, M., Tomioka, R., Lemm, S., Kawanabe, M., \& Muller, K. (2008). Optimizing Spatial filters for Robust EEG Single-Trial Analysis. IEEE Signal Processing Magazine, 25(1), 41-56. https://doi.org/10.1109/MSP.2008.4408441

5. Britannica. (n.d.). Posthypnotic amnesia. https://www.britannica.com/science/posthypnotic-amnesia

6. Cardeña, E., Jönsson, P., Terhune, D. B., \& Marcusson-Clavertz, D. (2013). The neurophenomenology of neutral hypnosis. Cortex, 49(2), 375-385. https://doi.org/10.1016/j.cortex.2012.04.001

7. Carelli, L., Solca, F., Faini, A., Meriggi, P., Sangalli, D., Cipresso, P., Riva, G., Ticozzi, N., Ciammola, A., Silani, V., \& Poletti, B. (2017). Brain-Computer Interface for Clinical Purposes: Cognitive Assessment and Rehabilitation. Biomed Research International, 2017, 1695290. https://doi.org/10.1155/2017/1695290

8. Casiglia, E., Tikhonoff, V., Albertini, F., Lapenta, A. M., Gasparotti, F., Finatti, F., Rossi, A. M., Zanette, G., Giacomello, M., Giordano, N., Favaro, J., \& Facco, E. (2018). The Mysterious Hypnotic Analgesia: Experimental Evidences. Psychology, 9(8), 1935-1956. https://doi.org/10.4236/psych.2018.98112

9. Casiglia, E., Tikhonoff, V., \& Facco, E. (2016). The Unconscious Experimentally Demonstrated by Means of Hypnosis. Psychology, 7(4), 469-479. https://doi.org/10.4236/psych.2016.74048

10. Casiglia, E., Tikhonoff, V., Giordano, N., Regaldo, G., Facco, E., Marchetti, P., Schiff, S., Tosello, M. T., Giacomello, M., Rossi, A. M., De Lazzari, F., Palatini, P., \& Amodio, P. (2012). Relaxation Versus Fractionation as Hypnotic Deepening: Do They Differ in Physiological Changes? International Journal of Clinical and Experimental Hypnosis, 60(3), 338-355. https://doi.org/10.1080/00207144.2012.675297

11. Casiglia, E., Finatti, F., Tikhonoff, V., Stabile, M. R., Mitolo, M., Gasparotti,F., Albertini, F., Lapenta, A. M., \& Venneri, A. (2019). Granone's Plastic Monoideism Demonstrated by Functional Magnetic Resonance Imaging (fMRI). Psychology, 10(4), 434-448. https://doi.org/10.4236/psych.2019.104030

12. Chertok, L. (1989). L’hypnose: Théorie, pratique et technique [Hypnosis: Theory, practice and technique]. Payot.

13. Cordi, M. J., Schlarb, A. A., \& Rasch, B. (2014). Deepening sleep by hypnotic suggestion. Sleep, 37(6), 1143-1152. https://doi.org/10.5665/sleep.3778

14. Council, J. R. (2002). A Historical Overview of hypnotizability assessment. American Journal of Clinical Hypnosis, 44(3-4), 199-208. https://doi.org/10.1080/00029157.2002.10403480 
15. Deivanayagi, S., \& Fernandez, P. (2007). Spectral Analysis of EEG Signals During Hypnosis. International Journal of Systemics, Cybernetics and Informatics. 75-80.

16. Delorme, A., \& Makeig, S. (2004). EEGLAB: an open-source toolbox for analysis of single-trial EEG dynamics. Journal of Neuroscience Methods, 134(1), 9-21. https://doi.org/10.1016/j.jneumeth.2003.10.009

17. De Pascalis, V., Ray, W. J., Tranquillo, I., \& D'Amico, D. (1998). EEG activity and heart rate during recall of emotional events in hypnosis: relationships with hypnotizability and suggestibility. International Journal of Psychophysiology, 29(3), 255-275. https://doi.org/10.1016/s0167-8760(98)00009-9

18. De Pascalis, V., \& Santarcangelo, E. L. (2020). Hypnotizability-Related Asymmetries: A Review. Symmetry, 12(6), 1015. https://doi.org/10.3390/sym12061015

19. Driel, J., Olivers, C., \& Fahrenfort, J. J. (2021). High-pass filtering artifacts in multivariate classification of neural time series data. Journal of Neuroscience Methods, 352(2021), 109080. https://doi.org/10.1016/j.jneumeth.2021.109080

20. Elkins, G. R. (2021). Hypnotizability: Emerging Perspectives and Research. International Journal of Clinical and Experimental Hypnosis, 69(1), 1-6. https://doi.org/10.1080/00207144.2021.1836934

21. Elkins, G. R., Barabasz, A. F., Council, J. R., \& Spiegel, D. (2015). Advancing Research and Practice: The Revised APA Division 30 Definition of Hypnosis. International Journal of Clinical and Experimental Hypnosis, 63(1), 1-9. https://doi.org/10.1080/00207144.2014.961870

22. Facco, E., Testoni, I., Ronconi, L., Casiglia, E., Zanette, G., \& Spiegel, D. (2017). Psychological features of hypnotizability: A first step towards its empirical definition. International Journal of Clinical and Experimental Hypnosis, 65(1), 98-119. https://doi.org/10.1080/00207144.2017.1246881

23. Freeman, R., Barabasz, A., Barabasz, M., \& Warner, D. (2000). Hypnosis and Distraction Differ in Their Effects on Cold Pressor Pain. American Journal of Clinical Hypnosis, 43(2), 137-148. https://doi.org/10.1080/00029157.2000.10404266

24. Friedlander, J., \& Sarbin, T. (1938). The depth of hypnosis. Journal of Abnormal and Social Psychology, 33(4), 453-475. https://doi.org/10.1037/h0056229

25. Frischolz, E. J., Spiegel, D., Trentalange, M. J., \& Spiegel, H. (2015). The hypnotic induction profile and absorption. American Journal of Clinical Hypnosis, 2 (57), 122 128. https://doi.org/10.1080/00029157.2015.967065

26. Giannakakis, G., Tsekos, N., Giannakaki, K., Michalopoulos, K., Vorgia, P., \& Zervakis, M. (2019). Seizure Detection using Common Spatial Patterns and Classification Techniques. 19th IEEE International Conference on Bioinformatics and Bioengineering (BIBE), (pp. 890-893). IEEE. 
27. Hildenbrand, A.K., Nicholls, E.G., Aggarwal, R., Brody-Bizar, E. and Daly, B.P. (2015). Symptom Checklist-90-Revised (SCL-90-R). In R.L. Cautin \& S.O. Lilienfeld (Eds.), The Encyclopedia of Clinical Psychology (pp.1-5). Wiley Online Library.

28. Ibáñez-Marcelo, E., Campioni, L., Phinyomark, A., Petri, G., \& Santarcangelo, E. L. (2019). Topology highlights mesoscopic functional equivalence between imagery and perception. NeuroImage, 200, 437-449. https://doi.org/10.1016/j.neuroimage.2019.06.044

29. Irimia, D. C., Ortner, R., Poboroniuc, M. S., Ignat, B. E., \& Guger, C. (2018). High Classification Accuracy of a Motor Imagery Based Brain-Computer Interface for Stroke Rehabilitation Training. Frontiers in Robotics and AI, 5, 130. https://doi.org/10.3389/frobt.2018.00130

30. Jamieson, G. A., \& Burgess, A. P. (2014). Hypnotic induction is followed by statelike changes in the organization of EEG functional connectivity in the theta and beta frequency bands in high-hypnotically susceptible individuals. Frontiers in Human Neuroscience, 8, 528. https://doi.org/10.3389/fnhum.2014.00528

31. Jensen, M. P., Adachi, T., \& Hakimian, S. (2015). Brain oscillations, hypnosis, and hypnotizability. American Journal of Clinical Hypnosis, 57(3), 230-253. https://doi.org/10.1080/00029157.2014.976786

32. Jensen, M. P., Battalio, S. L., Chan, J. F., Edwards, K. A., Day, M. A., Sherlin, L. H., \& Ehde, D. M. (2018). USE of neurofeedback and mindfulness to enhance response to hypnosis treatment in individuals with multiple sclerosis: Results from a Pilot Randomized Clinical Trial. International Journal of Clinical and Experimental Hypnosis, 66(3), 231-264. https://doi.org/10.1080/00207144.2018.1460546

33. Kohavi, R., \& Provost, F. (1998). Glossary of terms. Machine Learning-Special Issue on Applications of Machine Learning and the Knowledge Discovery Process. Machine Learning, 30, 271-274. https://doi.org/10.1023/A:1017181826899

34. Korger, W. (2007). Clinical and Experimental Hypnosis: In Medicine, Dentistry, and Psychology. Revised edition. Hauraki Publishing.

35. Kothe, C. A., \& Makeig, S. (2013). BCILAB: a platform for brain-computer interface development. Journal of neural engineering, 10(5), 056014. https://doi.org/10.1088/1741-2560/10/5/056014

36. Krol, L. R., Andreessen, L. M., \& Zander, T. O. (2018). Passive Brain-Computer Interfaces: A Perspective on Increased Interactivity. In C. S. Nam, A. Nijholt, \& F. Lotte (Eds.), Brain-Computer Interfaces Handbook: Technological and Theoretical Advances (pp. 69-86). CRC press.

37. Kropotov, Y. D. (2009). Quantitive EEG, event-related potentials and neurotherapy. Academic Press.

38. Krylov, V. I., Obukhov, N. V., Trofimov, V. I., \& Solnyshkina, I. E. (2020). Hypnotherapy for borderline psychic disorders in a multidisciplinary hospital. Neurology, Neuropsychiatry, Psychosomatics, 12(1), 33-38. https://doi.org/10.14412/2074-2711-2020-1-33-38 
39. Langlois, D., Chartier, S., \& Gosselin, D. (2010). An Introduction to Independent Component Analysis: InfoMax and FastICA algorithms. Tutorials in Quantitative Methods for Psychology, 6(1), 31-38. https://doi.org/10.20982/tqmp.06.1.p031

40. Laureanti, R., Bilucaglia, M., Zito, M., Circi, R., Fici, A., Rivetti, F., Valesi, R., Oldrini, C., Mainardi, L., \& Russo, V. (2020). Emotion assessment using Machine Learning and low-cost wearable devices. 42nd Annual International Conference of the IEEE Engineering in Medicine and Biology Society (EMBC'20), (pp. 576-579). IEEE.

41. Lecron, L. M. (1953). A method of measuring the depth of hypnosis. Journal of Clinical and Experimental Hypnosis, 1(2), 4-7. https://doi.org/10.1080/00207145308409812

42. Liu, Q., \& Wu, Y. (2012). Supervised Learning. In N. M. Seel (Ed.), Encyclopedia of the Sciences of Learning (pp. 192-211). Springer.

43. Lynn, S. J., \& Kirsch, I. (2005). Essentials of Clinical Hypnosis: An Evidence-based Approach. American Psychological Association.

44. McGeown, W. J., Mazzoni, G., Vannucci, M., \& Venneri, A. (2015). Structural and Functional Correlates of Hypnotic Depth and Suggestibility. Psychiatry Research, 231, 151-159. https://doi.org/10.1016/j.pscychresns.2014.11.015

45. Mitsar. (n.d.). WinEEG Research Software. https://mitsar-eeg.com/eeg-systemsolutions/wineeg-research-software/

46. Naseer, N., \& Hong, K. S. (2015). fNIRS-based brain-computer interfaces: a review. Frontiers in Human Neuroscience, 9,3. https://doi.org/10.3389/fnhum.2015.00003

47. Oakley, D., \& Halligan, P. (2013). Hypnotic suggestion: opportunities for cognitive neuroscience. Nat Rev Neurosci, 4(8), 565-576. https://doi.org/10.1038/nrn3538

48. Ozkan, N. F., \& Kahya, E. (2018). Classification of BCI Users Based on Cognition. Computational Intelligence and Neuroscience 2018, 6315187.

https://doi.org/10.1155/2018/6315187

49. Paoletti, P., Ben-Soussan, T. D., \& Glicksohn, J. (2020). Inner navigation and theta activity: from movement to cognition and hypnosis according to the sphere model of consciousness.In C. Mordeniz (Ed.), Hypnotherapy and Hypnosis. IntechOpen.

50. Papalia, E., Manzoni, D., \& Santarcangelo, E. L. (2014). Stabilizing posture through imagery. International Journal of Clinical and Experimental Hypnosis, 62(3), 292309. https://doi.org/10.1080/00207144.2014.901080

51. Proatech. (n.d.) BioEra, visual designer for biofeedback. http://bioera.net/index.shtml

52. Rainville, P., Hofbauer, R. K., Bushnell, M. C., Duncan, G. H., \& Price, D. D. (2002). Hypnosis modulates activity in brain structures involved in the regulation of consciousness. Journal of Cognitive Neuroscience, 14(6), 887-901. https://doi.org/10.1162/089892902760191117 
53. Ramoser, H., Müller-Gerking, J., \& Pfurtscheller, G. (2001). Optimal Spatial Filtering of Single Trial EEG During Imagined Hand Movement. IEEE transactions on rehabilitation engineering: a publication of the IEEE Engineering in Medicine and Biology Society,8(4), 441-446. https://doi.org/10.1109/86.895946

54. Ramsey, N. F., \& Millán, J. R., (2020). Handbook of Clinical Neurology. Elsevier.

55. Reis, H. T., Wheeler, L., \& Wolff, E. (1975). Multiple Pathways to Hypnotic Susceptibility: A New Scheme for Predicting the Depth of Hypnosis American. Journal of Clinical Hypnosis, 17(3), 175-184. https://doi.org/10.1080/00029157.1975.10403737

56. Renard, Y., Lotte, F., Gibert, G., Congedo, M., Maby, E., Delannoy, V., Bertrand, O., \& Lécuyer, A. (2010). An Open-Source Software Platform to Design, Test and Use Brain-Computer Interfaces in Real and Virtual Environments. Presence Teleoperators and Virtual environments, 19(1), 35-53. https://doi.org/10.1162/pres.19.1.35

57. Sabourin, M. E., Cutcomb, S. D., Crawford, H. J., \& Pribram, K. (1990). EEG correlates of hypnotic susceptibility and hypnotic trance: spectral analysis and coherence. International Journal of Psychophysiology, 10(2), 125-42. https://doi.org/10.1016/0167-8760(90)90027-b

58. Santarcangelo, E. L. (2014). New views of hypnotizability. Frontiers in behavioral neuroscience, 8, 224. https://doi.org/10.3389/fnbeh.2014.00224

59. Santarcangelo, E. L., \& Consoli, S. (2018). Complex Role of Hypnotizability in the Cognitive Control of Pain. Frontiers in Psychology, 9, 2272. https://doi.org/10.3389/fpsyg.2018.02272

60. Santos, M. S., Soares, J. P., Abreu, P., Araújo, H., \& Santos, J. (2018). CrossValidation for Imbalanced Datasets: Avoiding Overoptimistic and Overfitting Approaches. IEEE Computational Intelligence Magazine,13(4), 59-76. https://doi.org/10.1109/MCI.2018.2866730

61. Spina, V., Chisari, C., \& Santarcangelo, E. L. (2020). High Motor Cortex Excitability in Highly Hypnotizable Individuals: A Favourable Factor for Neuroplasticity? Neuroscience, 430, 125-130. https://doi.org/10.1016/j.neuroscience.2020.01.042

62. Szabó, C. (1993). The Phenomenology of the Experiences and the Depth of Hypnosis: Comparison of Direct and Indirect Induction Techniques. International Journal of Clinical and Experimental Hypnosis, 41(3), 225-233. https://doi.org/10.1080/00207149308414552

63. Tart, C. T. (1978). Quick and Convenient Assessment of Hypnotic Depth: Self-report Scales. American Journal of Clinical Hypnosis, 21(2-3), 186-207. https://doi.org/10.1080/00029157.1978.10403971

64. Tukaev, R. (2020). The Integrative: Theory of Hypnosis in the Light of Clinical Hypnotherapy. In C. Mordeniz (Ed.), Hypnotherapy and Hypnosis. IntechOpen.

65. Vaitl, D., Birbaumer, N., Gruzelier, J., Jamieson, G. A., Kotchoubey, B., Kübler, A., Lehmann, D., Miltner, W. H., Ott, U., Pütz, P., Sammer, G., Strauch, I., Strehl, U., 
Wackermann, J., \& Weiss, T. (2005). Psychobiology of Altered States of Consciousness. Psychological bulletin, 131(1), 98-127. https://doi.org/10.1037/00332909.131.1.98

66. Wagstaff, G. F. (2010). Hypnosis and the Relationship between trance, suggestion, expectancy and depth: some semantic and conceptual issues. American Journal of Clinical Hypnosis, 53(1), 47-59. https://doi.org/10.1080/00029157.2010.10401746

67. Weitzenhoffer, A. M. (1962). The significance of hypnotic depth in therapy. International Journal of Clinical and Experimental Hypnosis, 10(2), 75-78. https://doi.org/10.1080/00207146208415866

68. Williamson, A. (2019). What is hypnosis and how might it work? Palliative Care: Research and Treatment, 12. https://doi.org/10.1177/1178224219826581

69. Wolpaw, J., \& Wolpaw, E. (2012). Brain-Computer Interfaces: Principles and Practice. Published to Oxford Scholarship Online.

70. Zammouri, A., Moussa, A.A., \& Mebrouk, Y. (2018). Brain-computer interface for workload estimation: Assessment of mental efforts in learning processes. Expert Syst. Appl., 112, 138-147. https://doi.org/10.1016/j.eswa.2018.06.027

71. Zander, T. O., Andreessen, L. M., Berg, A., Bleuel, M., Pawlitzki, J., Zawallich, L., Krol, L. R., \& Gramann, K. (2017). Evaluation of a Dry EEG System for Application of Passive Brain-Computer Interfaces in Autonomous Driving. Frontiers in Human Neuroscience, 11, 78. https://doi.org/10.3389/fnhum.2017.00078

72. Zigmond, A. S., \& Snaith, R. P. (1983). The hospital anxiety and depression scale. Acta Psychiatrica Scandinavica, 67(6), 361-370. https://doi.org/10.1111/j.16000447.1983.tb09716.x

73. Бизюк А.П., Вассерман Л.И., Иовлев Б.В. (2005). Применение интегративного теста тревожности (ИТТ) Методические рекомендации. [Application of the Integrative Anxiety Test (IAT)]. Изд. Психоневрологического института им. В.М. Бехтерева.

74. Доскин В.А., Лаврентьева Н.А., Мирошников Н.П., Шарай В.Б. (1973). Tecm дифферениированной самооченки функиионального состояния [The test of differentiated self-assessment of the functional state]. Вопросы психологии. 


\section{Tables}

Table 1. Participants' data

\begin{tabular}{|c|c|c|c|c|c|}
\hline $\begin{array}{l}\text { Patient's } \\
\text { Code }\end{array}$ & Gender & $\begin{array}{l}\text { Age, } \\
\text { years }\end{array}$ & Diagnosis, ICD-10 & $\begin{array}{l}\text { Number of } \\
\text { sessions }\end{array}$ & $\begin{array}{l}\text { Medications, mg } \\
\text { per day }\end{array}$ \\
\hline $\mathrm{A}$ & $\mathrm{M}$ & 34 & $\begin{array}{l}\text { F41.1 } \\
\text { Generalized anxiety } \\
\text { disorder+ F45.8 } \\
\text { Other somatoform disorder }\end{array}$ & 7 & Tofisopam, 100 \\
\hline $\mathrm{E}$ & $\mathrm{F}$ & 58 & $\begin{array}{l}\text { F40.0 } \\
\text { Agoraphobia }\end{array}$ & 6 & Escitalopram, 10 \\
\hline G & $\mathrm{F}$ & 45 & $\begin{array}{l}\text { F41.1 } \\
\text { Generalized anxiety } \\
\text { disorder }\end{array}$ & 4 & Sertraline, 50 \\
\hline $\mathrm{S}$ & $\mathrm{F}$ & 49 & $\begin{array}{l}\text { F40.01 } \\
\text { Agoraphobia with panic } \\
\text { disorder }\end{array}$ & 3 & Escitalopram, 10 \\
\hline $\mathrm{O}$ & $\mathrm{F}$ & 33 & $\begin{array}{l}\text { F32.1 } \\
\text { Moderate depressive } \\
\text { episode+ F41.1 } \\
\text { Generalized anxiety } \\
\text { disorder }\end{array}$ & 2 & Fluoxetine, 40 \\
\hline $\mathrm{N}$ & $\mathrm{M}$ & 35 & $\begin{array}{l}\text { F41.1 } \\
\text { Generalized anxiety } \\
\text { disorder }\end{array}$ & 2 & Fluoxetine, 20 \\
\hline $\mathrm{V}$ & $\mathrm{M}$ & 35 & $\begin{array}{l}\text { F41.1 } \\
\text { Generalized anxiety } \\
\text { disorder }\end{array}$ & 2 & - \\
\hline $\mathrm{C}$ & $\mathrm{F}$ & 22 & $\begin{array}{l}\text { F32.1 } \\
\text { Moderate depressive } \\
\text { episode+ F41.1 } \\
\text { Generalized anxiety } \\
\text { disorder }\end{array}$ & 2 & Sertraline, 100 \\
\hline $\mathrm{T}$ & $\mathrm{F}$ & 34 & $\begin{array}{l}\text { F41.1 } \\
\text { Generalized anxiety } \\
\text { disorder }\end{array}$ & 1 & - \\
\hline
\end{tabular}


Table 2. The 10-fold cross-validation test results for the classification accuracy of the states "W" and "T"

\begin{tabular}{|c|c|c|c|c|c|}
\hline \multirow[t]{2}{*}{ Patient } & \multirow[t]{2}{*}{ Session } & \multicolumn{4}{|c|}{ Accuracy for the corresponding band, $\mathrm{M} \pm \mathrm{SD}, \%$} \\
\hline & & $1.5-45 \mathrm{~Hz}$ & $1.5-8 \mathrm{~Hz}$ & $1.5-14 \mathrm{~Hz}$ & 4-15 Hz \\
\hline \multirow[t]{8}{*}{ A } & 1 & $96 \pm 8$ & $86 \pm 18$ & $98 \pm 6$ & $94 \pm 9.17$ \\
\hline & 2 & $93.5 \pm 10.01$ & $95.5 \pm 9.07$ & $86.5 \pm 14.33$ & $72.5 \pm 26.48$ \\
\hline & 3 & $88 \pm 18.33$ & $72 \pm 31.24$ & $86 \pm 25.38$ & $86 \pm 25.38$ \\
\hline & 4 & $95 \pm 15$ & $83 \pm 15.84$ & $95 \pm 10$ & $95 \pm 10$ \\
\hline & 5 & $94 \pm 9.17$ & $89.67 \pm 17.16$ & $92.33 \pm 13$ & $96.33 \pm 7.37$ \\
\hline & 6 & $98 \pm 6$ & $87 \pm 15.52$ & $92 \pm 13.27$ & $96 \pm 8$ \\
\hline & 7 & $84.17 \pm 21.87$ & $93.33 \pm 13.33$ & $83.33 \pm 22.36$ & $86.67 \pm 16.33$ \\
\hline & $\mathrm{M} \pm \mathrm{SD}$ & $92.67 \pm 4.86$ & $86.64 \pm 7.75$ & $90.45 \pm 5.32$ & $89.5 \pm 8.65$ \\
\hline \multirow[t]{6}{*}{$\mathrm{E}$} & 1 & $97.5 \pm 7.5$ & $82 \pm 15.68$ & $88.5 \pm 16.13$ & $95 \pm 10$ \\
\hline & 2 & $100 \pm 0$ & $90.5 \pm 11.72$ & $93 \pm 15.52$ & $86.5 \pm 19.11$ \\
\hline & 3 & $100 \pm 0$ & $91 \pm 11.14$ & $100 \pm 0$ & $100 \pm 0$ \\
\hline & 4 & $95 \pm 10$ & $93 \pm 15.52$ & $91 \pm 15.78$ & $92 \pm 24$ \\
\hline & 6* & $100 \pm 0$ & $96 \pm 8$ & $94 \pm 18$ & $96 \pm 8$ \\
\hline & $\mathrm{M} \pm \mathrm{SD}$ & $98.5 \pm 2.24$ & $90.5 \pm 5.22$ & $93.3 \pm 4.3$ & $93.9 \pm 5.03$ \\
\hline \multirow[t]{5}{*}{$\mathrm{G}$} & 1 & $94.33 \pm 8.7$ & $96 \pm 8$ & $98.33 \pm 5$ & $96 \pm 12$ \\
\hline & 2 & $98.33 \pm 5$ & $92.33 \pm 18.14$ & $94.67 \pm 11.08$ & $93 \pm 15.52$ \\
\hline & 3 & $100 \pm 0$ & $100 \pm 0$ & $100 \pm 0$ & $96.33 \pm 7.37$ \\
\hline & 4 & $98 \pm 6$ & $98 \pm 6$ & $98 \pm 6$ & $98 \pm 6$ \\
\hline & $\mathrm{M} \pm \mathrm{SD}$ & $97.67 \pm 2.39$ & $96.58 \pm 3.27$ & $97.75 \pm 2.23$ & $95.83 \pm 2.08$ \\
\hline \multirow[t]{4}{*}{$S$} & 1 & $100 \pm 0$ & $100 \pm 0$ & $97.5 \pm 7.5$ & $95.5 \pm 9.07$ \\
\hline & 2 & $97.5 \pm 7.5$ & $100 \pm 0$ & $100 \pm 0$ & $100 \pm 0$ \\
\hline & 3 & $97.5 \pm 7.5$ & $97.5 \pm 7.5$ & $97.5 \pm 7.5$ & $97.5 \pm 7.5$ \\
\hline & $\mathrm{M} \pm \mathrm{SD}$ & $98.33 \pm 1.44$ & $99.17 \pm 1.44$ & $98.33 \pm 1.44$ & $97.67 \pm 2.25$ \\
\hline \multirow[t]{3}{*}{$\mathrm{O}$} & 1 & $100 \pm 0$ & $100 \pm 0$ & $97.5 \pm 7.5$ & $97.5 \pm 7.5$ \\
\hline & 2 & $100 \pm 0$ & $100 \pm 0$ & $97.5 \pm 7.5$ & $87.5 \pm 16.78$ \\
\hline & $\mathrm{M} \pm \mathrm{SD}$ & $100 \pm 0$ & $100 \pm 0$ & $97.5 \pm 0$ & $92.5 \pm 7.07$ \\
\hline \multirow[t]{3}{*}{$\mathrm{N}$} & 1 & $96 \pm 8$ & $98 \pm 6$ & $94 \pm 18$ & $98 \pm 6$ \\
\hline & 2 & $100 \pm 0$ & $100 \pm 0$ & $100 \pm 0$ & $100 \pm 0$ \\
\hline & $\mathrm{M} \pm \mathrm{SD}$ & $98 \pm 2.83$ & $99 \pm 1.41$ & $97 \pm 4.24$ & $99 \pm 1.41$ \\
\hline \multirow[t]{3}{*}{$\mathrm{V}$} & 1 & $91 \pm 15.78$ & $93.5 \pm 10.01$ & $98 \pm 6$ & $95.5 \pm 9.07$ \\
\hline & 2 & $100 \pm 0$ & $98 \pm 6$ & $100 \pm 0$ & $100 \pm 0$ \\
\hline & $\mathrm{M} \pm \mathrm{SD}$ & $95.5 \pm 6.36$ & $95.75 \pm 3.18$ & $99 \pm 1.41$ & $97.75 \pm 3.18$ \\
\hline \multirow[t]{3}{*}{$\mathrm{C}$} & 1 & $100 \pm 0$ & $95 \pm 15$ & $81.67 \pm 22.91$ & $96.67 \pm 10$ \\
\hline & 2 & $100 \pm 0$ & $77.5 \pm 29.36$ & $93.33 \pm 20$ & $93.33 \pm 20$ \\
\hline & $\mathrm{M} \pm \mathrm{SD}$ & $100 \pm 0$ & $86.25 \pm 12.37$ & $87.5 \pm 8.24$ & $95 \pm 2.36$ \\
\hline
\end{tabular}

\footnotetext{
* session 5 has been excluded from analysis
} 
Table 3. Results of assessing the accuracy of the classification model for discrimination of states "W" and "T" on the data of the second (and subsequent) sessions

\begin{tabular}{|c|c|c|c|c|c|}
\hline \multirow[t]{2}{*}{ Patients } & \multirow[t]{2}{*}{ Sessions } & \multicolumn{4}{|c|}{ Accuracy for the corresponding band, $\mathrm{M} \pm \mathrm{SD}, \%$} \\
\hline & & $1.5-45 \mathrm{~Hz}$ & $1.5-8 \mathrm{~Hz}$ & $1.5-14 \mathrm{~Hz}$ & 4-15 Hz \\
\hline \multirow[t]{7}{*}{ A } & 2 & 74.31 & 52.08 & 74.65 & 66.32 \\
\hline & 3 & 80.0 & 75.34 & 91.51 & 89.86 \\
\hline & 4 & 99.48 & 64.83 & 87.66 & 88.98 \\
\hline & 5 & 69.09 & 66.94 & 94.62 & 91.94 \\
\hline & 6 & 90.85 & 69.82 & 90.24 & 87.8 \\
\hline & 7 & 79.73 & 66.32 & 80.76 & 73.54 \\
\hline & $\mathrm{M} \pm \mathrm{SD}$ & $82.24 \pm 11.12$ & $65.89 \pm 7.72$ & $86.57 \pm 7.48$ & $83.07 \pm 10.52$ \\
\hline \multirow[t]{5}{*}{$\mathrm{E}$} & 2 & $54.75(98.42)^{*}$ & 38.29 & 70.89 & 80.38 \\
\hline & 3 & $54.18(72.76)^{* *}$ & 65.63 & 53.56 & 83.9 \\
\hline & 4 & 71.82 & 69.7 & 81.52 & 84.55 \\
\hline & $6 * * *$ & 70.06 & 44.19 & 59.01 & 84.01 \\
\hline & $\mathrm{M} \pm \mathrm{SD}$ & $62.7 \pm 9.54$ & $54.45 \pm 15.53$ & $66.24 \pm 12.49$ & $83.21 \pm 1.9$ \\
\hline \multirow[t]{4}{*}{$\mathrm{G}$} & 2 & 87.10 & 91.13 & 91.13 & 73.92 \\
\hline & 3 & 88.98 & 97.31 & 90.05 & 81.72 \\
\hline & 4 & 75.78 & 94.3 & 89.46 & 87.75 \\
\hline & $\mathrm{M} \pm \mathrm{SD}$ & $83.95 \pm 7.14$ & $94.25 \pm 3.09$ & $90.21 \pm 0.85$ & $81.13 \pm 6.93$ \\
\hline \multirow[t]{3}{*}{$S$} & 2 & 53.03 & 93.64 & 95.76 & 53.64 \\
\hline & 3 & 94.3 & 87.03 & 78.16 & 75.95 \\
\hline & $\mathrm{M} \pm \mathrm{SD}$ & $73.67 \pm 29.18$ & $90.34 \pm 4.67$ & $86.96 \pm 12.45$ & $64.8 \pm 15.78$ \\
\hline $\mathrm{O}$ & 2 & 61.46 & 89.58 & 89.24 & 88.89 \\
\hline $\mathrm{N}$ & 2 & 97.09 & 93.6 & 96.8 & 96.51 \\
\hline $\mathrm{V}$ & 2 & 95.06 & 90.41 & 88.08 & 94.48 \\
\hline $\mathrm{C}$ & 2 & 71.92 & 61.15 & 66.15 & 82.31 \\
\hline \multicolumn{2}{|c|}{$\begin{array}{c}\text { Average for all } \\
\text { sessions, } \mathrm{M} \pm \mathrm{SD}\end{array}$} & $77.32 \pm 14.89$ & $74.28 \pm 17.96$ & $82.59 \pm 12.53$ & $82.44 \pm 10.35$ \\
\hline
\end{tabular}


bioRxiv preprint doi: https://doi.org/10.1101/2021.11.13.467562; this version posted November 15,2021 . The copyright holder for this preprint (which was not certified by peer review) is the author/funder, who has granted bioRxiv a license to display the preprint in perpetuity. It is made available under aCC-BY-NC-ND 4.0 International license.

\section{Figures}

Figure 1. Screenshot captured during a session with real-time monitoring of changes in the power of rhythms in the standard frequency bands of the 21-channel EEG

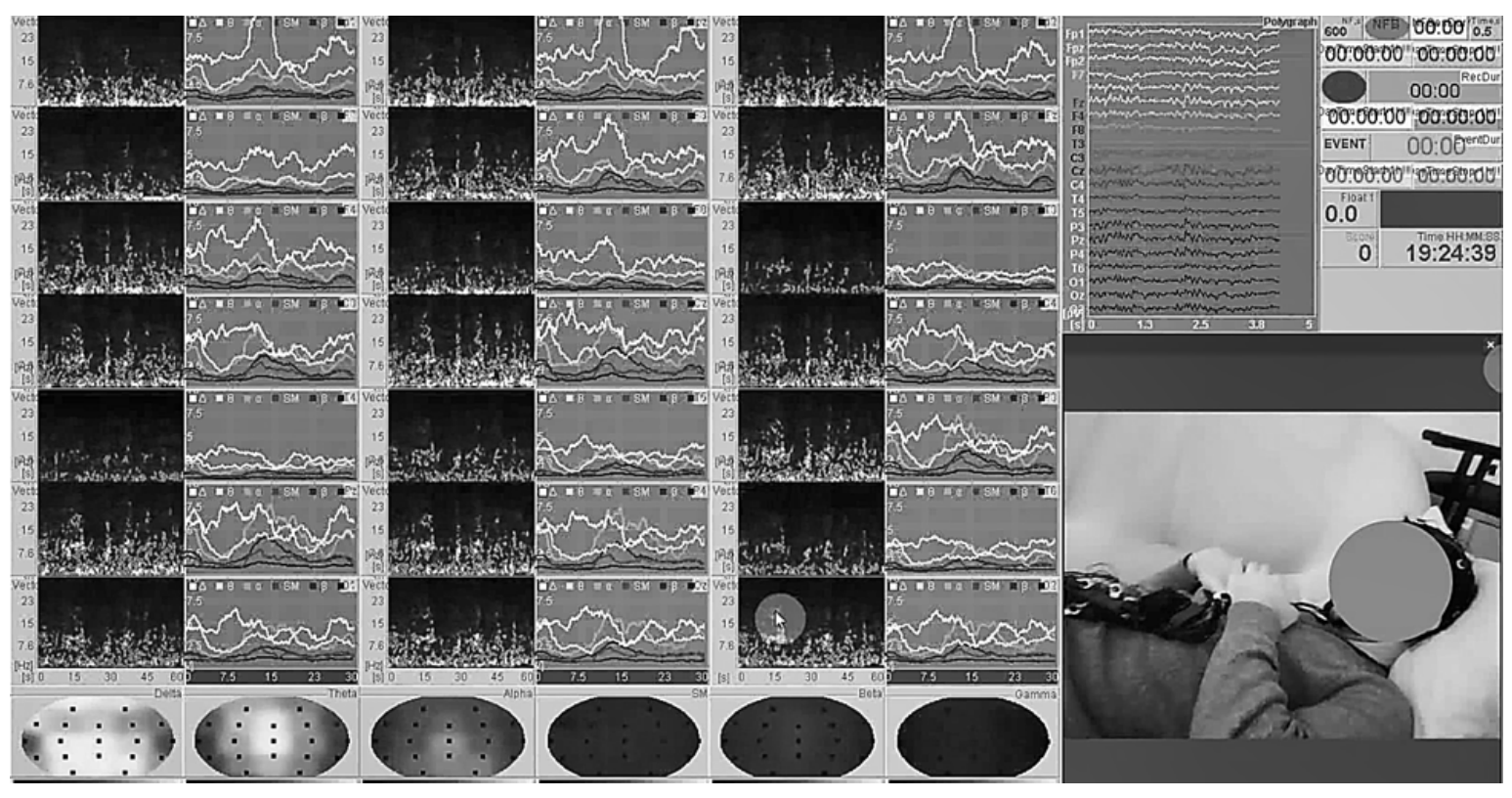


Figure 2. An example of topograms displaying the results of a statistical comparison of the average values of the absolute power of the spectra between the deep trance and wakefulness periods in standard frequency ranges for three patients (sessions for displaying are randomly selected). The color scale is in $\mu \mathrm{V}^{2}$

\section{Session № (days after $1^{\text {st }}$ session)}

1

1

Band
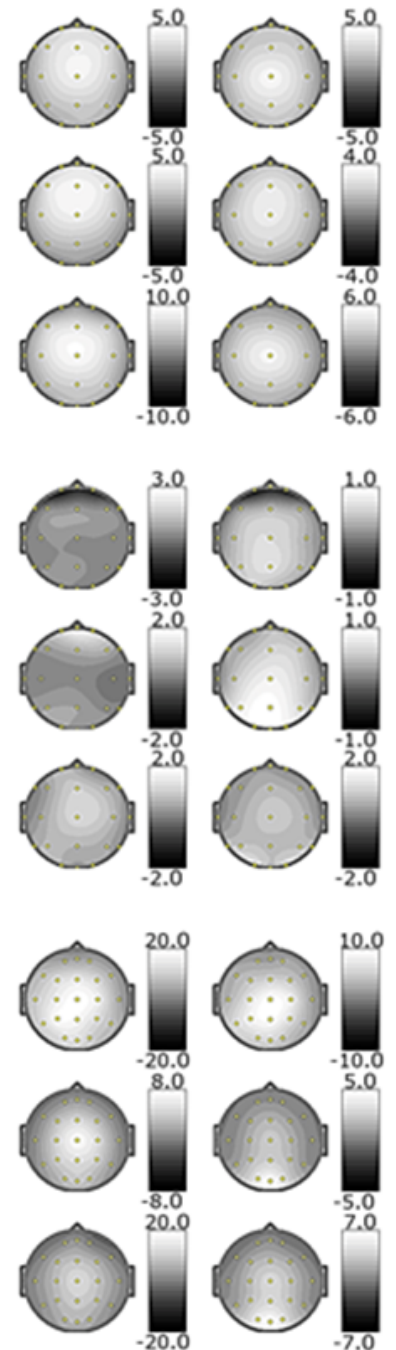

Delta

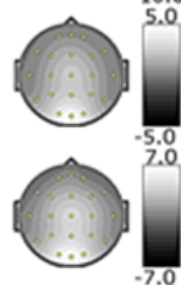

Theta
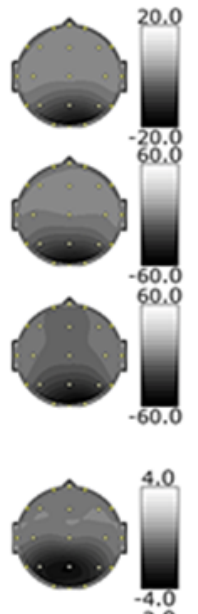

Patient E
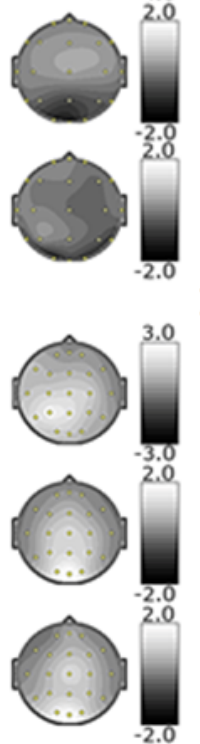

Alpha

Patient G
Patient A
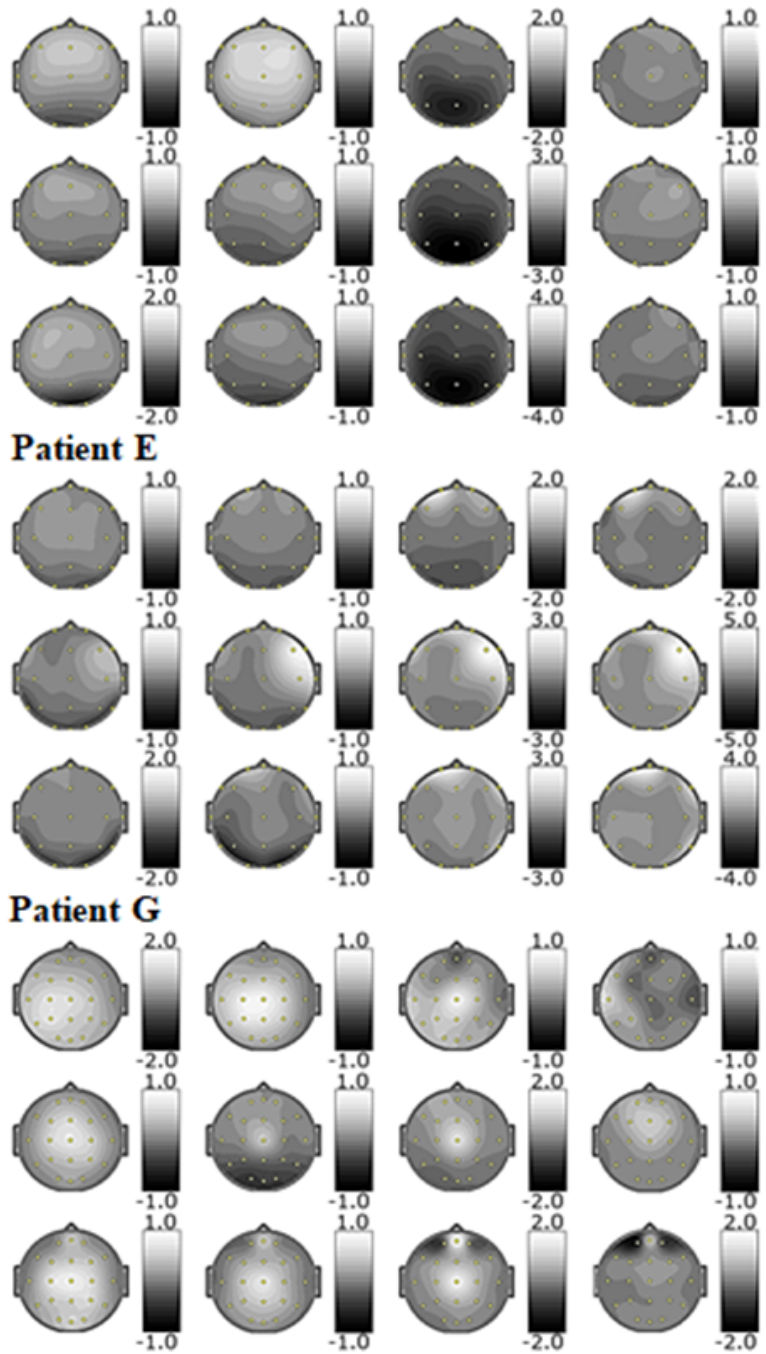

Beta2

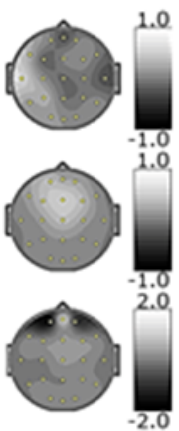

Gamma 
bioRxiv preprint doi: https://doi.org/10.1101/2021.11.13.467562; this version posted November 15, 2021. The copyright holder for this preprint (which was not certified by peer review) is the author/funder, who has granted bioRxiv a license to display the preprint in perpetuity. It is made available under aCC-BY-NC-ND 4.0 International license.

Figure 3. Screenshot of the "predictive" curve at the end of the online session with patient A on the seventh visit (1.5-45 Hz band was used)

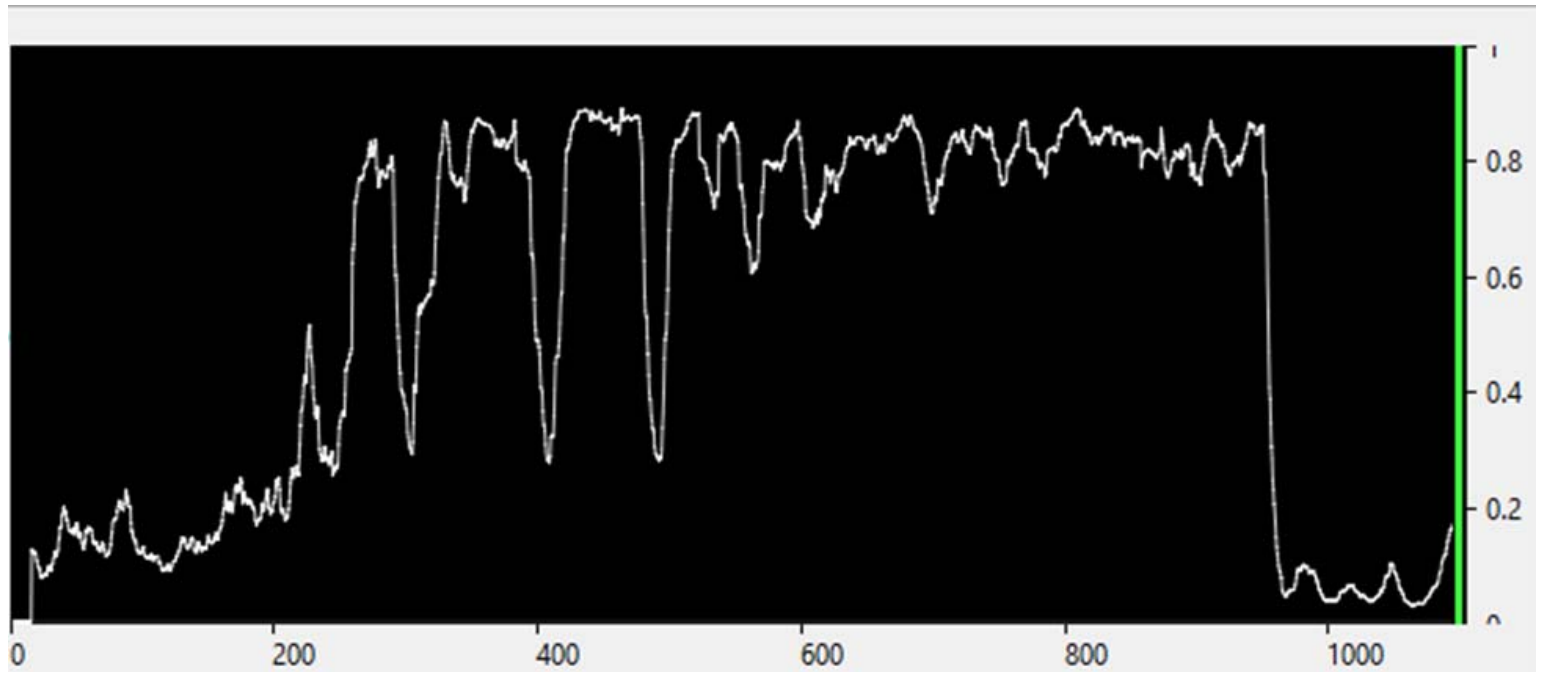

Figure 4. "Native" curve of the seventh session with patient A (1.5-45 Hz band was used)

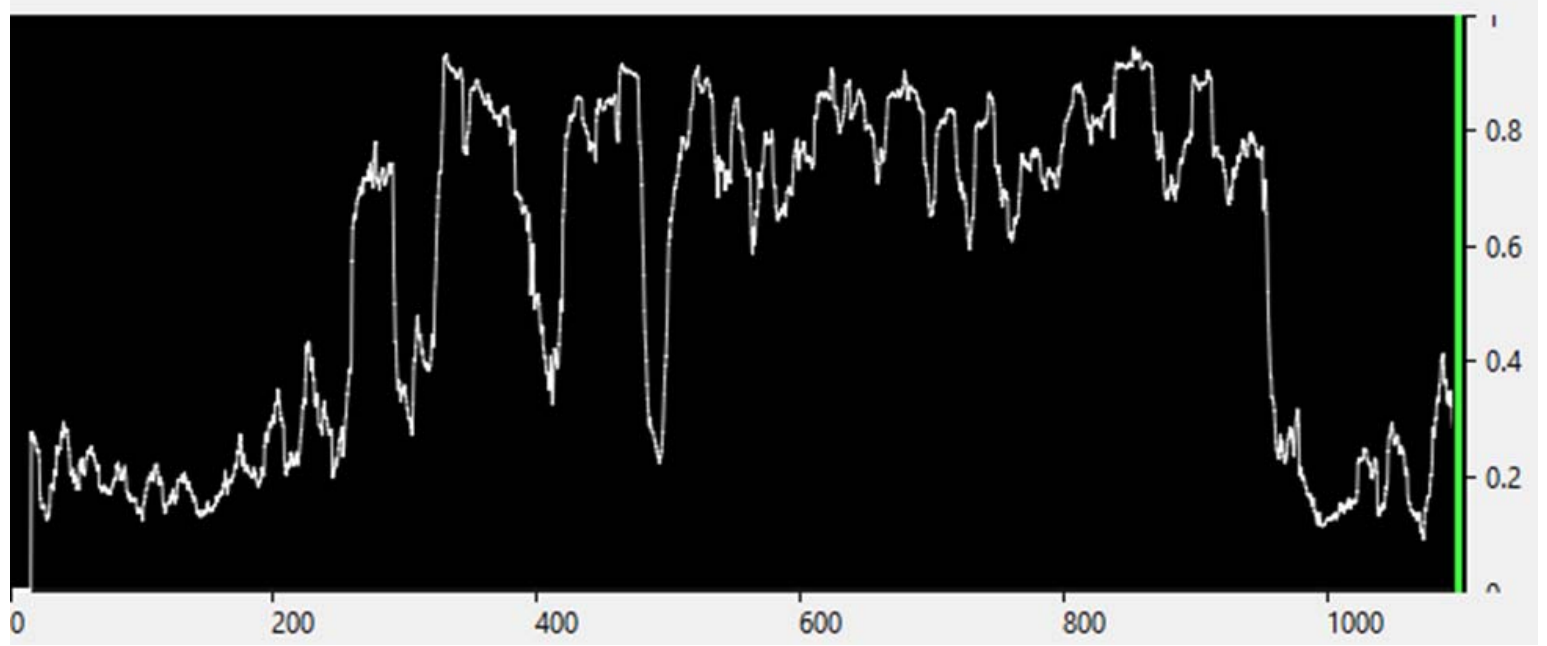

